\title{
Targeting tumor perfusion and oxygenation to improve the outcome of anticancer therapy ${ }^{1}$
}

\author{
Bénédicte F. Jordan ${ }^{1}$ and Pierre Sonveaux ${ }^{2 *}$ \\ ${ }^{1}$ Nuclear Magnetic Resonance Research Group, Louvain Drug Research Institute, Université catholique de Louvain Medical School, Brussels, Belgium \\ 2 Pole of Pharmacology, Institute of Experimental and Clinical Research, Université Catholique de Louvain Medical School, Brussels, Belgium
}

Edited by:

François E. Paris, INSERM, France

Reviewed by:

Carine Michiels, University of Namur, Belgium

David Waugh, Queen's University

Belfast, Northern Ireland

*Correspondence:

Pierre Sonveaux, University of Louvain Medical School, Pole of

Pharmacology, Avenue Emmanuel

Mounier 52 Box B1.53.09, B-1200

Brussels, Belgium.

e-mail: pierre.sonveaux@uclouvain.be
Radiotherapy and chemotherapy are widespread clinical modalities for cancer treatment. Among other biological influences, hypoxia is a main factor limiting the efficacy of radiotherapy, primarily because oxygen is involved in the stabilization of the DNA damage caused by ionizing radiations. Radiobiological hypoxia is found in regions of rodent and human tumors with a tissue oxygenation level below $10 \mathrm{mmHg}$ at which tumor cells become increasingly resistant to radiation damage. Since hypoxic tumor cells remain clonogenic, their resistance to the treatment strongly influences the therapeutic outcome of radiotherapy. There is therefore an urgent need to identify adjuvant treatment modalities aimed to increase tumor $\mathrm{pO}_{2}$ at the time of radiotherapy. Since tumor hypoxia fundamentally results from an imbalance between oxygen delivery by poorly efficient blood vessels and oxygen consumption by tumor cells with high metabolic activities, two promising approaches are those targeting vascular reactivity and tumor cell respiration. This review summarizes the current knowledge about the development and use of tumor-selective vasodilators, inhibitors of tumor cell respiration, and drugs and treatments combining both activities in the context of tumor sensitization to $X$-ray radiotherapy. Tumor-selective vasodilation may also be used to improve the delivery of circulating anticancer agents to tumors. Imaging tumor perfusion and oxygenation is of importance not only for the development and validation of such combination treatments, but also to determine which patients could benefit from the therapy. Numerous techniques have been developed in the preclinical setting. Hence, this review also briefly describes both magnetic resonance and non-magnetic resonance in vivo methods and compares them in terms of sensitivity, quantitative or semi-quantitative properties, temporal, and spatial resolutions, as well as translational aspects.

Keywords: hypoxia, tumor vasculature, vasodilation, oxygen consumption, radiotherapy, chemotherapy, provascular anticancer therapy, tumor imaging

\section{INTRODUCTION}

Hypoxia, a partial pressure of oxygen $\left(\mathrm{pO}_{2}\right)$ below physiological needs, is a limiting factor affecting the efficiency of radiotherapy. Indeed, the reaction of reactive oxygen species (ROS, produced by water radiolysis) with DNA is readily reversible unless oxygen stabilizes the DNA lesion. While normal tissue oxygenation is around $40 \mathrm{mmHg}$, both rodent and human tumors possess regions of tissue oxygenation below $10 \mathrm{mmHg}$, at which tumor cells become increasingly resistant to radiation damage (radiobiological hypoxia; Gray et al., 1953). Because of this so-called "oxygen enhancement effect" (Figure 1), the radiation dose required to achieve the same biologic effect is about three times higher in the absence of oxygen than in the presence of normal levels of oxygen (Gray et al., 1953; Horsman and van der Kogel, 2009). Hypoxic tumor cells, which are therefore more resistant to radiotherapy than well oxygenated ones, remain clonogenic, and contribute to

\footnotetext{
${ }^{1}$ This paper was originally published as "Jordan, B. F., and Sonveaux, P. (2011). Targeting tumor perfusion and oxygenation modulates hypoxia and cancer sensitivity to radiotherapy and systemic therapies" in Advances in Cancer Therapy, ed. H. Gali-Muhtasib (Rijeka: Intech), 289-312.
}

the therapeutic outcome of fractionated radiotherapy (Rojas et al., 1992).

Tumor hypoxia results from the imbalance between oxygen delivery by poorly efficient blood vessels and oxygen consumption by tumor cells with high metabolic activities. On the one hand, oxygen delivery is impaired by structural abnormalities present in the tumor vasculature (Munn, 2003). They include caliber variations with dilated and narrowed single branches of tumor vessels, non-hierarchical vascular networks, disturbed precapillary architecture, and incomplete vascular walls. These structural abnormalities cause numerous functional impairments, i.e., increased transcapillary permeability, increased vascular permeability, interstitial hypertension, and increased flow resistance (Boucher et al., 1996; McDonald and Baluk, 2002). It is however important to note that, although hastily formed immature tumor microvessels lack smooth muscle layer(s) and are therefore unable to provide autoregulation, it is not uncommon to find mature blood vessels with smooth muscle layers and neural junctions inside slowgrowing tumors (e.g., most human tumors; Feron, 2004). On the other hand, the altered tumor cell metabolism with elevated metabolic rates also contributes to the occurrence of hypoxic regions 


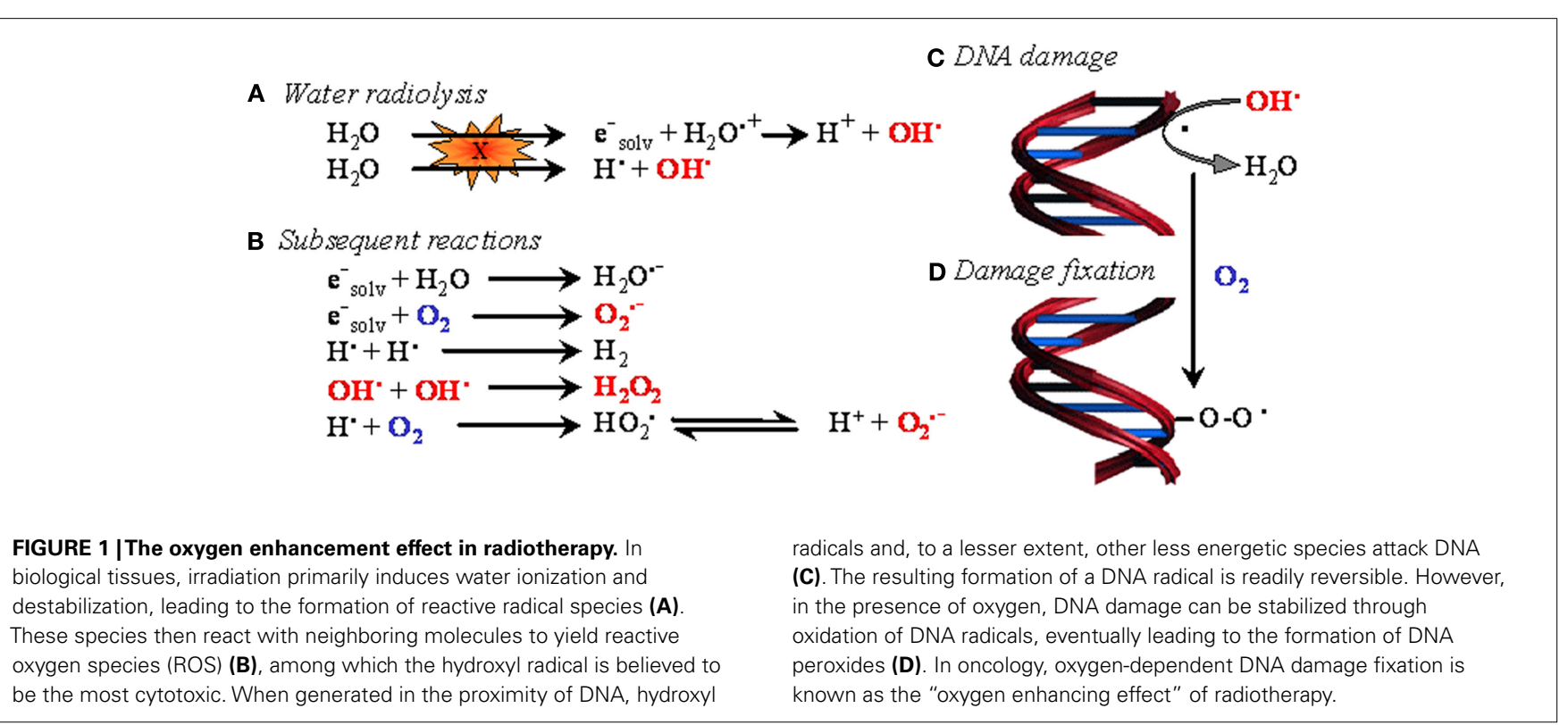

in tumors and further causes extracellular acidification. Tumor hypoxia occurs in two ways: chronic hypoxia (or diffusion-limited hypoxia), and acute hypoxia (or perfusion-limited or fluctuating hypoxia; Figure 2). Chronic hypoxia has classically been thought to result from long diffusion distances between tumor vessels as the consequence of the more rapid expansion of tumor cells than that of the supporting vasculature (Vaupel et al., 1989). It is now well established that steep longitudinal gradients of $\mathrm{pO}_{2}$ along the vascular tree, as opposed to radial diffusion of oxygen, can largely contribute to deficiencies in tumor oxygen supply (Dewhirst et al., 1999). The origin of acute hypoxia in tumors is not firmly established. The commonly held view has been that acute hypoxia results primarily from vascular stasis, which stems from one of three causes: (1) vascular collapse in regions of high tumor interstitial pressure, (2) vessel plugging by leukocytes, and (3) impingement of tumor cells on the vascular lumen. It has been demonstrated that temporal instability in tumor red blood cell flux could lead to transient hypoxia (Kimura et al., 1996) and Dewhirst linked temporal changes in microvessel red blood cell flux to changes in the oxygen content in the same vessel (Dewhirst et al., 1996). Factors that may contribute to flow fluctuations include arteriolar vasomotion and rapid vascular modeling (Dewhirst et al., 1996; Patan et al., 1996; Baudelet et al., 2004, 2006). More recent studies indicate a widespread presence of fluctuating hypoxia in solid tumors (Cardenas-Navia et al., 2008).

The effect of tumor hypoxia on the response to treatment by ionizing radiation has been demonstrated in a multitude of experimental studies. In a series of clinical studies in the early nineties, Vaupel and others showed definitively that measurements of $\mathrm{pO}_{2}$ by polarographic microelectrodes provided useful criteria for predicting the response of tumors to radiation therapy (Gatenby et al., 1988; Hockel et al., 1993; Okunieff et al., 1993; Stone et al., 1993; Thomas et al., 1994). These results stimulated considerable efforts in defining and evaluating therapeutic approaches designed to overcome tumor hypoxia as source of resistance (Horsman and van der Kogel, 2009). A particular area under focus is thus to combine radiotherapy with treatments that increase tumor $\mathrm{pO}_{2}$. Other approaches consist to chemically radiosensitize hypoxic cells or alternatively to exploit hypoxia as a mean to selectively kill the resistant population of hypoxic cells. Before the advent of imaging methods able to provide non-invasively oxygen estimation, animal, and clinical studies were generally designed to evaluate the effect of a given treatment on tumor $\mathrm{pO}_{2}$ as measured by Eppendorf or histological markers of tumor hypoxia. The clinical end points were generally locoregional control and survival. Modifiers of oxygen delivery tested in clinical trials included hyperbaric oxygen therapy (HBO), oxygen and carbogen breathing. Hypoxic cell radiosensitizers (possessing a selective toxicity for the radioresistant hypoxic cells) tested in clinical trials included metronidazole, misonidazole, nimorazole, and tirapazamine. In a systematic review, Overgaard (2007) identified 10,108 patients in 86 randomized trials designed to modify tumor hypoxia in patients treated with curative attempted primary radiation therapy alone. Overall modification of tumor hypoxia significantly improved the effect of radiotherapy for the outcome of locoregional control and with an associated significant overall survival benefit. No significant influence was found on the incidence of distant metastases or on the risk of radiation-related complications. From this metaanalysis, the authors concluded in 2007 that "Ample data exist to support a high level of evidence for the benefit of hypoxic modification. However, hypoxic modification still has no impact on general clinical practice."

Currently, the most advanced therapeutic interventions used in the clinic to target tumor hypoxia are either the DAHANCA (Danish head and neck cancer) trial, the application of the ARCON (Accelerated radiotherapy, carbogen, and nicotinamide) protocol, and phase III studies with Tirapazamine. In the DAHANCA phase III study, nimorazole has been used as hypoxic radiosensitizer on 422 patients, and it was shown that this compound improves the effect of radiotherapeutic management in head and neck cancer 


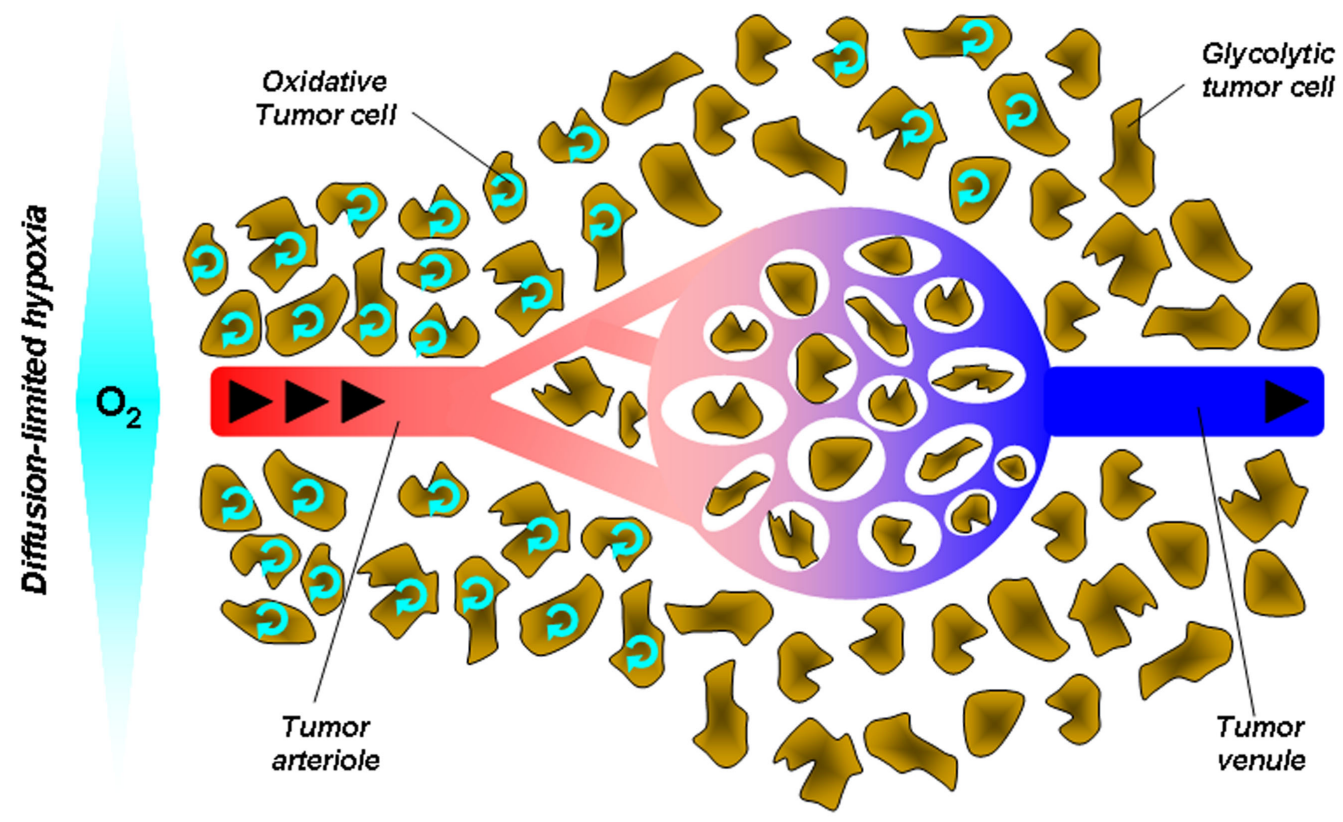

$\mathrm{O}_{2}$

\section{Perfusion-limited hypoxia}

FIGURE 2 | Tumor hypoxia. Hypoxia in tumors results from a mismatch between the oxygen supply by poorly efficient blood vessels and oxygen consumption by metabolically overactive tumor cells. This simplified cartoon depicts two main forms of hypoxia. Diffusion-limited hypoxia refers to a gradient of oxygen deprivation from the nearest perfused blood vessels toward tumor cells at increasing distances from this vessel. It originates from high-rate of oxygen extraction though layers of cells within a loosened vascular network. Perfusion-limited hypoxia refers to oxygen deprivation along the vascular tree from the tumor margin toward the tumor core. Poor oxygen delivery has many causes in tumors, including high-rate of oxygen extraction at the tumor margin, decreased red blood cell deformability, and stacking, increased blood viscosity due to water extraction, vascular disorganization, and angiogenesis. Arrows represent the blood flow.
(Overgaard et al., 1998). Since these results, nimorazole administration became part of the standard irradiation protocol for Head and Neck cancer in Denmark. However, these findings have had no impact on general clinical practice except for Denmark because earlier generations of these agents induced rather severe peripheral neuropathy and because nearly all of the individual phase III trials yielded negative or inconclusive results (Ang, 2010). The ARCON protocol consists in the combination of accelerated radiotherapy to overcome tumor cell proliferation, carbogen breathing to overcome diffusion-limited hypoxia, and nicotinamide to minimize capillary bed shutdown and thereby reduce perfusion-related acute hypoxia. Phase I and II clinical trials have shown the feasibility and tolerability of the treatment and have produced promising results in term of tumor control, in particular in cancer of the head and neck and bladder (Kaanders et al., 2002). A large improvement in survival was demonstrated using this approach during radiotherapy for bladder cancer. The randomized multicentre phase III trial, designed and coordinated at Mount Vernon Cancer Centre, demonstrated a $13 \%$ benefit in overall survival when radiotherapy was combined with carbogen and nicotinamide compared to radiotherapy alone (Hoskin et al., 2009). Results from a large phase III trial launched to test this regimen will become available within the next 2 years. Finally, Tirapazamine (TPZ) has attracted interest after preclinical studies showing that in addition to augmenting the cytotoxicity of both radiation and cisplatin, this compound selectively kills hypoxic cells (Rischin et al., 2001, 2005). Phase I and II studies of the combination of TPZ with radiation and cisplatin were performed on patients with locally advanced head and neck carcinoma. On the basis of the phase II data, a large international phase III trial was launched (Peters et al., 2010). Surprisingly, the combination did not show any evidence of improvement in overall survival. Nevertheless, patients were not previously screened for tumor hypoxia; the study was multicentric with some centers enrolling fewer than five patients and a consequent decrease in the quality of radiotherapy planning and delivery which can have dramatic consequences on outcome (Ang, 2010).

This review will explore two strategies to radiosensitizer tumors to X-rays: to increase oxygen delivery by exploiting the reactivity of mature tumor vessels (the so-called "provascular" approach) and to decrease oxygen consumption by tumor cells. The goal of the provascular approach is to temporarily increase tumor perfusion and oxygenation through pharmacological interventions. Accordingly, radiotherapy could benefit from tumor reoxygenation whereas a decrease in interstitial pressure could facilitate 
tumor accessibility to circulating drugs. Alternatively, a second approach is to decrease the oxygen consumption by tumor cells since theoretical modeling studies demonstrated that reducing $\mathrm{O}_{2}$ consumption was far more efficient at reducing tumor hypoxia than increasing blood $\mathrm{pO}_{2}$ or flow (Secomb et al., 1995). We will also describe attempts to combine both approaches that can be considered as complementary strategies. The evaluation and validation of these adjuvant therapies (Table 1) require imaging techniques capable of monitoring tumor perfusion and oxygenation.

From the clinical analyses cited above, it also appeared that the variation in the results among the trials reflects a considerable heterogeneity among tumors and that patient individualization would be mandatory for the success of such therapeutic approach. There is therefore an essential need to predict individually the presence of hypoxic regions in tumors. Based on individual tumor characteristics and/or the ability to alleviate tumor hypoxia, it will become possible to adapt the individual treatment either by delivering optimal radiation doses into the resistant areas or by delivering an associated treatment for potentiating the efficacy of radiation treatments. In the early nineties, invasive techniques such as polarographic electrodes have been used in clinical studies to definitely establish the value of hypoxia as a predictive marker of the response of tumors to irradiation. Although this method was successful in demonstrating the central role played by tumor hypoxia in the clinical response to radiation therapy, it has never been used in standard clinical practice because of its invasiveness and the difficulty to systematically carry out longitudinal studies in individual patients. Fortunately, it is now possible to estimate tumor oxygenation by using minimally or non-invasive techniques. This will be the purpose of the last part of this review.

\section{IMPROVING OXYGEN DELIVERY TO THE TUMOR: THE PROVASCULAR APPROACH}

Tumors are highly heterogeneous and this heterogeneity extends to the tumor vasculature (see Introduction). Beside neovessels that are the target of anti-angiogenic agents, human and rodent tumors also contain blood vessels that are structurally mature (Mattson et al., 1978; Peterson and Mattson, 1984). These vessels possess the minimal contractile features (such as pericytes or vascular smooth muscle cells) endowing them with vasocontractile properties. The intrinsic reactivity of tumor-feeding vessels modulates oxygen delivery and the accessibility of circulating drugs to the tumor. A selective and transient dilation of these vessels should thus improve the tumor response to radiotherapy (which depends on tumor oxygenation) and chemotherapy (which depends on perfusion and on the vascular exchange area). We termed this approach "provascular" to contrast with antivascular and antiangiogenic approaches that are destructive by nature (Sonveaux, 2008). The net effect of systemic vasodilation on tumor $\mathrm{pO}_{2}$ is unpredictable because it primarily depends on the arrangement of vessels (in series or in parallel) between the tumor and surrounding host tissues (Zlotecki et al., 1995). The key issue to resolve is thus to identify tumor-selective vasodilators. Treatment optimization would also require to monitor on individual bases the tumor response to treatment, preferentially using early surrogate, predictive, and non-invasive markers.

\section{NITRIC OXIDE AND ENDOTHELIN-1 RELATED STRATEGIES}

Physiologically, the vascular tone is determined by the balance between nitric oxide (NO, a potent vasodilator) and endothelin1 (ET-1, a potent vasoconstrictor; Sonveaux and Feron, 2005). A number of studies have explored the functionality and the provascular exploitability of these two systems, as described below.

Table 1 | Pharmacological interventions able to radiosensitize tumors through selective vasodilation and/or decreased oxygen consumption by tumor cells.

\begin{tabular}{|c|c|c|c|c|}
\hline Treatment & $\begin{array}{l}\text { Tumor-selective } \\
\text { vasodilation }\end{array}$ & $\begin{array}{l}\text { Decreased } \mathrm{O}_{2} \\
\text { consumption }\end{array}$ & $\begin{array}{l}\text { Radiosensitization } \\
\text { to X-rays }\end{array}$ & Reference \\
\hline NO donor drugs & Yes & $\begin{array}{l}\text { Yes } \\
\text { (S-nitrosocaptopril) }\end{array}$ & Yes & $\begin{array}{l}\text { Sonveaux et al. (2009), Jordan et al. (2000), Segers et al. } \\
\text { (2010), Jordan et al. (2010), Jordan and Gallez (2010) }\end{array}$ \\
\hline Nitrites & Yes & Yes & Yes & Frerart et al. (2008) \\
\hline S-nitrosylated hemoglobin & Potentially & ND & ND & Sonveaux et al. (2005), Sonveaux et al. (2007b) \\
\hline Insulin & No & Yes & Yes & Jordan et al. (2002), Jordan et al. (2006a) \\
\hline X-rays & Yes & Yes & Yes & $\begin{array}{l}\text { Sonveaux et al. (2009), Sonveaux et al. (2002), } \\
\text { Sonveaux et al. (2003, 2007a), Crokart et al. (2005b) }\end{array}$ \\
\hline $\begin{array}{l}\text { Endothelin-1 receptor A } \\
\text { inhibitors }\end{array}$ & Yes & ND & Yes & Sonveaux et al. (2004), Martinive et al. (2006) \\
\hline $\begin{array}{l}\text { Anti-angiogenic agents } \\
\text { SU-5416 and ZD-6474 }\end{array}$ & No & Yes & Yes & Ansiaux et al. $(2006,2009)$ \\
\hline Meta-iodobenzylguanidine & ND & Yes & ND & Biaglow et al. (1998) \\
\hline Glucocorticoids & No & Yes & Yes & Crokart et al. (2007) \\
\hline $\begin{array}{l}\text { Non-steroidal } \\
\text { anti-inflammatory drugs }\end{array}$ & No & Yes & Yes & Crokart et al. (2005a) \\
\hline Mild hyperthermia & $\begin{array}{l}\text { Yes } \\
\text { (moderately) }\end{array}$ & Yes & yes & $\begin{array}{l}\text { Lepock et al. (1987), Kelleher et al. (1995), Moon et al. } \\
\text { (2010), Brizel et al. (1996), Vujaskovic et al. (2003), } \\
\text { Jones et al. (2003, 2005) }\end{array}$ \\
\hline
\end{tabular}




\section{Exogenous and endogenous NO}

$\mathrm{NO}$ was initially investigated for its vasodilatory activity and NO donors were anticipated to improve the therapeutic efficacy of chemo- and radiotherapy upon combinational delivery (Sonveaux et al., 2009). We first considered the effect of the application of exogenous NO on tumor hemodynamic parameters and radiation response. This was performed by systemic administration of NO donor compounds, including isosorbide dinitrate, (Jordan et al., 2000) xanthinol nicotinate, (Segers et al., 2010), and $S$-nitrosocaptopril (Jordan et al., 2010). The stimulation of the production of endogenous NO was also achieved by administration of insulin (Jordan et al., 2002). All treatments resulted in a transient acute improvement of experimental tumor oxygenation with a consecutive increase in tumor radiosensitivity upon sequential administration of X-rays during the reoxygenation window identified for each tumor model (Jordan et al., 2010). The reoxygenation effect was shown to be due to an increase in tumor blood flow for Isosorbide Dinitrate, Xanthinol Nicotinate, and $S$-nitrosocaptopril, using either dynamic contrast-enhanced magnetic resonance imaging (DCE-MRI), where the number of perfused voxels and/or Ktrans, Kep, or Vp parameters was increased (see Dynamic Contrast-Enhanced MRI), or patent blue staining (Jordan and Gallez, 2010). Importantly, for some co-treatments, the increase in blood flow occurred concomitantly with a decrease in the rate of oxygen consumption by tumor cells. Inhibition of tumor cell respiration is the main mechanism accounting for insulin-induced tumor reoxygenation (see below).

Endogenous NO is produced by a series of enzymes collectively termed NO-synthases (NOS). The endothelial isoform, eNOS, is adapted for the local stimulation of vasodilation following a response to stimuli that release calcium from intracellular stores and promote a calcium-calmodulin-dependent release of eNOS from its inhibitory complex with caveolin-1 (Cav-1; Arnold et al., 1977; Michel et al., 1997). This mode of activation allows the transient production of micromolar amounts of $\mathrm{NO}$ responsible for vasodilatation. Using myography, we showed that this system is insensitive to classical eNOS stimulators (such as acetylcholine) selectively in tumor arterioles, thus suggesting that strategies able to restore eNOS activity would selectively target tumor vessels (Sonveaux et al., 2002). Among different treatments, we have found that ionizing radiations themselves were able to restore the normal vasodilatory properties of tumor vessels. X-rays, through the production of ROS, indeed induce an increase in eNOS expression concomitantly with a decrease in Cav-1 expression, which removes a functional brake promoting eNOS activation (Sonveaux et al., 2002, 2009). Irradiations further stimulate NO production through the ROS-dependent activation of the PI3 kinase pathway, a well described pathway supporting Akt-mediated eNOS phosphorylation (on Ser1177, human sequence) and activation (Sonveaux et al., 2003, 2007a). We documented that radiationinduced vasodilation takes an active part in the antitumor effects of X-rays by showing that eNOS inhibition between the first and second irradiation of a clinical regimen of fractionated radiotherapy results in the total loss of the antitumor efficacy of the second dose, whereas eNOS inhibition before a single dose does not preclude cytotoxic effects (Sonveaux et al., 2002). Active vasodilation after each of the consecutive doses of fractionated radiotherapy is associated with a window of tumor reoxygenation that offers a scientific rationale for the clinical use of radiotherapy in its fractionated mode.

\section{S-nitrosylated hemoglobin and nitrites}

A smart delivery of exogenous NO would help to resolve the Steal Effect, a process through which systemic vasodilation may in fact reduce tumor perfusion and oxygenation by redirecting blood to normal blood vessels that are generally more sensitive to vasoactive treatments and constitute a denser network (Zlotecki et al., 1995). Using hemoglobin ( $\mathrm{Hb})$ is an interesting approach because $\mathrm{Hb}$ is a physiological NO carrier (in the form of $S$-nitrosothiol) poised to deliver NO selectively in hypoxic tissues such as tumors (Sonveaux et al., 2005). NO delivery, indeed, is possible only after the conformational change associated with $\mathrm{Hb}$ deoxygenation (Jia et al., 1996; Stamler et al., 1997; McMahon et al., 2002). Using cellfree human $S$-nitrosylated $\mathrm{Hb}(\mathrm{SNO}-\mathrm{Hb})$ in rats, we documented a transient increase in tumor perfusion, but only when $\mathrm{SNO}-\mathrm{Hb}$ was delivered in oxygenated blood (i.e., intra-arteriolar injection or intravenous injection concomitantly with carbogen breathing; Sonveaux et al., 2005). In deoxygenated blood, SNO-Hb would otherwise readily deoxygenate and release $\mathrm{NO}$ at the site of delivery. While increased tumor perfusion at low dose $\mathrm{SNO}-\mathrm{Hb}$ is primarily attributable to central effects (i.e., baroreceptor inhibition), $\mathrm{SNO}-\mathrm{Hb}$ at higher doses could act as a tumor-selective vasodilator and could therefore be used as a radiosensitizing treatment. Inhalation of the NO donor gas ethyl nitrite, which promotes the $\mathrm{S}$-nitrosylation of intra-erythrocytic $\mathrm{Hb}$ in the lungs, could have the same effects while minimizing toxic side effects associated with the administration of naked $\mathrm{Hb}$ (Moya et al., 2002; Sonveaux et al., 2007b).

While the use of SNO-Hb exploits hypoxia as a mean to selectively deliver NO to tumors, one can also take advantage of the low $\mathrm{pH}$ coupled to the high metabolic activities of many solid tumors. Nitrites for example can be reduced to NO either by enzymatic catalysis (nitrite reductase activities of xanthine oxidase, eNOS, and $\mathrm{Hb}$ ) or by non-enzymatic disproportionation, and these processes are facilitated in an acidic microenvironment (Zweier et al., 1999; Godber et al., 2000; Modin et al., 2001; Angelo et al., 2006; Vanin et al., 2007). They have been used clinically as an antidote for cyanide poisoning (Holland and Kozlowski, 1986) which also indicates that they can be safely administrated to humans. We therefore tested whether the low $\mathrm{pH}$ of tumors (on average $\mathrm{pH}$ 6.7) could be exploited to generate $\mathrm{NO}$ from nitrites selectively in tumors. We observed ex vivo that nitrite-induced vasodilation was more pronounced at $\mathrm{pH}$ 6.7 compared to $\mathrm{pH} 7.4$ (Frerart et al., 2008). We also found that the bioactivity of nitrites at low $\mathrm{pH}$ encompassed NOmediated inhibition of tumor cell respiration, which indicates that the robust and transient increase in tumor $\mathrm{pO}_{2}$ after nitrite delivery to mice is the result of the combination of vasoactive and metabolic responses. When administered to reach a plasma concentration of $100 \mu \mathrm{M}$ in mice, nitrites sensitized tumors to radiotherapy (Frerart et al., 2008). Further clinical applications are however confronted to financial issues: clinical trials are now warranted whereas nitrites or their use in cancer therapy can not be patented. 


\section{Endothelin-1 inhibitors}

Endothelin-1 (ET-1) is a strong vasoconstrictor and an autocrine growth factor produced by tumor cells (Shichiri et al., 1991; Haynes and Webb, 1994). It has a key role in the accommodation of vasoactive blood vessels to variations in intraluminal pressure: ET-1 mediates the myogenic tone, a vasoconstriction that buffers perfusion changes when the blood pressure increases (Huang and Koller, 1997). In tumors, the constant exposure arterioles to ET-1 results in an increased myogenic tone that can be detected ex vivo (Sonveaux et al., 2004). We reasoned that it constituted a reserve for vasorelaxation that could be exploited to sensitize tumors to radioand chemotherapy. ET-1 induces vasoconstriction when binding to $\mathrm{ET}_{\mathrm{A}}$ receptors expressed by contractile vascular cells (Maguire and Davenport, 1995). Using the $\mathrm{ET}_{\mathrm{A}}$ antagonist BQ123, we observed ex vivo a vasodilation selectively in tumor vessels (compared to size-matched vessels from non-malignant tissues) that translated in vivo into increased tumor perfusion and oxygenation (Sonveaux et al., 2004). Both responses were tumor-selective and transient. BQ123 as a pretreatment therefore improved the antitumor effects of X-ray radiotherapy and cyclophosphamide (after systemic delivery; Sonveaux et al., 2004; Martinive et al., 2006).

\section{NORMALIZATION EFFECT OF ANTI-ANGIOGENIC AGENTS}

Given that anti-angiogenic agents will likely be combined with radiation therapy, it is critical to understand alterations in tumor oxygenation and perfusion, as well as to define optimal time points for the delivery of radiation. Our group previously studied the modifications in the tumor environment early after treatment with the anti-angiogenic agent thalidomide, with a special focus on a possible normalization of the tumor vasculature (Jain, 2001; Tong et al., 2004) that could be beneficial for radiotherapy. Our results showed an increase in tumor $\mathrm{pO}_{2}$ during the first 2 days of thalidomide treatment, which was likely the result of the ability of thalidomide to modify tumor microenvironmental parameters such as the vascular supply and tumor perfusion, as shown by DCE-MRI (see Dynamic Contrast-Enhanced MRI) and histological analysis using the endothelial marker CD31 (Ansiaux et al., 2005). Indeed, the histological analysis revealed profound modifications in the vascular supply: a reduction in the number of tumor microvessels after thalidomide treatment together with a dilation of the remaining vessels with no decrease in the tumor vascular density. The perfusion measured by DCE-MRI showed an increased plasma volume fraction (see Dynamic ContrastEnhanced MRI), which could be explained by the shift to larger blood vessel diameters as observed in histology analysis, perhaps due to compensation for the loss of small vessels. Interestingly, similar observations were not obtained using more specific antiangiogenic agents such as SU-5416 or ZD-6474 (Ansiaux et al., 2006, 2009). For these compounds, tumor reoxygenation was rather due to a decrease in the rate of oxygen consumption by tumor cell and no normalization effect was observed in the tumor models under study (see below). We hypothesized that specific inhibition of vascular endothelial growth factor (VEGF) signaling via VEGFR2 by SU-5416 or ZD-6474 may have been compensated by another angiogenic pathway such as basic fibroblast growth factor (bFGF), platelet-derived growth factor (PDGF), transforming growth factor (TGF)- $\beta$, or Tie-2 signaling; (Stratmann et al., 1998;
Folkman et al., 2001) contrary to thalidomide which acts on different angiogenic pathways. It is nevertheless important to note that these findings are specific to the tumor models under study, since ZD-6474 was described earlier to be able to decrease both flow and permeability in human colon tumors (Bradley et al., 2008) and was able to induce transient normalization of the vasculature in gliomas (Claes et al., 2008).

\section{DECREASING OXYGEN CONSUMPTION BY TUMOR CELLS}

Tumor oxygenation is a matter of supply and demand. Whereas the provascular strategy intends to improve oxygen supply, several strategies are aimed at decreasing oxygen consumption by tumor cells rendering molecular $\mathrm{O}_{2}$ available for the stabilization of radiation-induced DNA damage. Indeed, theoretical modeling studies demonstrated that reducing $\mathrm{O}_{2}$ consumption could be more efficient at reducing tumor hypoxia than increasing blood $\mathrm{pO}_{2}$ or flow (Secomb et al., 1995). Two main targets can be considered for inhibiting oxygen consumption: (i) direct interference with the mitochondrial respiratory chain (at different levels), and (ii) modulation of the redox status to change the mitochondrial membrane potential (Pilkington et al., 2008) the final aim being a subsequent increase in tumor $\mathrm{pO}_{2}$ and enhancement of the efficacy of radiotherapy.

In contrast to provascular strategies, Laser Doppler flowmetry, DCE-MRI and electron paramagnetic resonance (EPR) oximetry have revealed that the radiosensitizing effects of these treatments are primarily caused by a decrease in the rate of oxygen consumption by tumor cells, thus allowing oxygen to be redirected from a metabolic fate to the stabilization of DNA lesions. Indeed, apart from NO donors, all the treatments described below did not show any significant increase in tumor blood flow concomitant to the increase in tumor oxygenation. Some of them even showed a decrease in tumor blood flow that was counteracted by the dramatic decrease in oxygen consumption by tumor cells (i.e., insulin and NS-398). In addition, regarding NO-mediated treatments, our models showed that the radiotherapeutic response not only depended on the tumor $\mathrm{pO}_{2}$ but also on the net level of $\mathrm{NO}$ achieved at the time of irradiation, $\mathrm{NO}$ itself being able to stabilize irradiation-induced DNA lesions in vivo (Jordan et al., 2004).

The first drug that was described to inhibit oxygen consumption in tumors was meta-iodobenzylguanidine (MIBG), which causes an inhibition of the mitochondrial site I electron transfer, inhibition of $\mathrm{NAD}(\mathrm{P}) \mathrm{H}$ oxidation, and is described to alter tumor glycolysis by inhibiting oxygen consumption (Biaglow et al., 1998). We consecutively focused on different innovative treatments that may alter oxygen consumption by tumor cells, as listed below.

\section{INSULIN}

This hormone was known to increase blood flow in human skeletal muscle and was postulated to be an important modulator of tumor oxygenation (Jordan et al., 2002). Indeed, we showed that insulin had a profound effect on tumor oxygenation that was not due to an increase in tumor blood flow but to a decrease in tumor cell oxygen consumption. The increase in tumor oxygenation resulted in an important enhancement in the sensitivity of tumors to irradiation. The likely scenario involves a stimulation of eNOS and a consequent increase in NO release. As NO 
regulates mitochondrial respiration by virtue of reversible interactions with cytochrome $c$ oxidase (complex IV), an increase in NO release consequently decreased cell respiration (Jordan et al., 2002). A preclinical study confirmed the dose-dependant increase in tumor oxygenation and radiation sensitivity by insulin, without any increase in the radiation toxicity for normal tissues (Jordan et al., 2006a).

\section{GLUCOCORTICOIDS}

Earlier work had demonstrated that the administration of cortisone to rats resulted in both the inhibition of oxygen consumption and the uncoupling of oxidative phosphorylation in liver mitochondria (Kimberg et al., 1968). Glucocorticoids seemed to decrease the cytochrome $c$ oxidase (complex IV) activity of isolated rat kidney mitochondria by a direct mechanism (Simon et al., 1998). Our group showed an important increase in tumor oxygenation induced by an effect on oxygen consumption. Decreased oxygen consumption could be explained by the capacity of glucocorticoids to inhibit cytochrome $c$ oxidase of the mitochondrial respiratory chain. The result of this increase in tumor oxygenation was an improvement of the radiation efficacy by a factor of 1.7 (Crokart et al., 2007).

\section{ANTI-INFLAMMATORY DRUGS}

Several reports indicated that many non-steroidal antiinflammatory drugs (NSAIDs) uncouple mitochondrial oxidative phosphorylation with important consequences on cell oxygen consumption. However, it was suggested that the response was dependent on the dose as well as on the type of NSAIDs. For the first time, our group reported that the administration of NSAIDs induced a dramatic increase in tumor oxygenation explained by reduced oxygen consumption. An increase in the tumor response was observed when the irradiation was applied at the time of maximal reoxygenation (Crokart et al., 2005a).

\section{THYROID HORMONES}

Chronic alteration in the thyroid status has been shown to affect mitochondrial oxygen consumption in skeletal muscle (Gredilla et al., 2001). Also, studies have demonstrated that hypothyroidism slows down the neoplastic process, whereas administration of a thyroid hormone preparation restores tumor growth rates (Shoemaker and Dagher, 1979; Mishkin et al., 1981; Theodossiou et al., 1999). In humans, several case reports have indicated a prolonged survival in the presence of hypothyroidism (Hercbergs and Leith, 1993; Cristofanilli et al., 2005). Moreover, a decrease in the thyroid function may also serve to favorably influence the response to treatment. Finally, patients presented an enhanced response rate to chemotherapy and survived significantly longer under hypothyroidism (Hercbergs et al., 2003). Our group recently demonstrated that the thyroid status is associated with a significant change in tumor radiosensitivity since the regrowth delay was increased in hypothyroid mice compared to euthyroid mice. Mechanistically, we demonstrated that the higher level of tumor oxygenation in hypothyroid mice results from a significant reduction in the oxygen consumption rate of tumors (Jordan et al., 2007).

\section{NO DONORS}

We recently tested whether $S$-nitrosocaptopril, a molecule combining a NO donor and an angiotensin converting enzyme inhibitor (ACE inhibitor), could temporarily improve the hemodynamic status of experimental tumors. We identified a time window during which tumor oxygenation was improved, as a result of a combined effect on tumor blood flow and oxygen consumption. Consequently, the administration of $S$-nitrosocaptopril contributed to the increase in efficacy of radiation therapy, an effect that was not observed with captopril alone (Jordan et al., 2010).

\section{ANTI-ANGIOGENIC AGENTS}

As stated earlier, two anti-angiogenic agents, SU-5416 and ZD6474 , have also been identified as potent inhibitors of oxygen consumption (Ansiaux et al., 2006, 2009). Our major findings regarding those specific anti-angiogenic agents were the following: (a) SU-5416 and ZD-67474 both induce an increase in tumor oxygenation at an early phase of treatment (after 2 days of daily injections); (b) this tumor reoxygenation can be exploited to increase the efficacy of combined radiotherapy; (c) the mechanism of increase in tumor oxygenation does not involve a "normalization" of the tumor vasculature as described previously for thalidomide in the same tumor model (Ansiaux et al., 2005) but is consistent with the decrease in the rate of oxygen consumption by the tumor cells. Indeed, at this early stage of the treatment, no apparent remodeling of the tumor vasculature and no changes in tumor perfusion and permeability parameters were observed, using histological and DCE-MRI analysis, respectively. We however demonstrated a reduction in tumor oxygen consumption after those treatments. The reduction factor in oxygen consumption observed was sufficient to abolish tumor hypoxia, as we reported previously using the treatments listed above.

\section{HYPERTHERMIA: COMBINING PROVASCULAR AND OXYGEN CONSUMPTION EFFECTS IN A SINGLE TREATMENT}

Hyperthermia is a potent adjuvant therapy with radiotherapy and chemotherapy, and the perfect illustration of a strategy combining transient, local vasodilatation with the inhibition of tumor cell respiration. The heat treatment consists of elevating the temperature of tumors to a supra-physiological range of $40-45^{\circ} \mathrm{C}$ at which tumor reoxygenation occurs with limited skin toxicity. Hyperthermia induces a graded response in tissues characterized by decreased oxygen consumption at temperatures $\geq 40^{\circ} \mathrm{C}$, vasodilatation between 41 and $41.5^{\circ} \mathrm{C}$, and vascular damage above $42^{\circ} \mathrm{C}$. Although direct tumor cell killing was demonstrated in vitro at higher temperatures, long-term tumor control has never been demonstrated using hyperthermia as the sole treatment modality. Vasodilation only modestly contributes to tumor reoxygenation at the low thermal doses. Increased $\mathrm{pO}_{2}$ rather primarily results from changes in oxygen consumption in the target cells, and at least two different processes have been identified to contribute to this response. It is now well demonstrated that an important target of heat is proteins among which enzymes of the respiratory chain are more sensitive to heat inactivation/denaturation than glycolytic enzymes (Lepock et al., 1987; Kelleher et al., 1995). But the inhibition of mitochondrial respiration by heat lasts longer than the 
turnover time of respiratory enzymes, suggesting the existence of an additional mechanism. Dewhirst in collaboration with our team (Moon et al., 2010) recently demonstrated that mild hyperthermia activates the transcription factor hypoxia-inducible factor 1 (HIF-1) through an hypoxia-independent mechanism involving the sequential activation of Extracellular signal-Regulated Kinases (ERK) by heat shock, ERK-induced upregulation of the expression of the Noxl subunit of $\mathrm{NAD}(\mathrm{P}) \mathrm{H}$ oxidase, increased ROS production by NAD $(\mathrm{P}) \mathrm{H}$ oxidase, ROS-induced HIF- $1 \alpha$ protein stabilization, and, ultimately, HIF-1 activation. HIF-1 target genes include most glycolytic enzymes and transporters as well as major pro-angiogenic molecules such as VEGF. Among these genes, we showed that pyruvate dehydrogenase kinase 1 (PDK1) largely mediates the inhibition of mitochondrial respiration by heat in tumor cells through inhibiting pyruvate dehydrogenase $(\mathrm{PDH})$, i.e., the enzyme coupling glycolysis to the tricarboxylic acid (TCA) cycle (Moon et al., 2010). Furthermore, consistent with the increase in VEGF expression that we also observed in heat-treated tumors, we documented an increased vascular density in perfused tumor areas where oxygen is extracted from the blood. Tumor reoxygenation by mild hyperthermia is thus a multifaceted process involving the combination of decreased $\mathrm{O}_{2}$ consumption by tumor cells and increased $\mathrm{O}_{2}$ delivery by blood vessels. This and the fact that reoxygenation occurs at thermal doses lower than those inducing vascular damage justifies the use of mild hyperthermia as a combination treatment notably with radiotherapy. Although several clinical trials have confirmed that combining heat and radiotherapy is indeed associated with better patient treatment outcome (Brizel et al., 1996; Jones et al., 2003, 2005; Vujaskovic et al., 2003) the future clinical development of hyperthermia strongly relies on designing tools allowing for homogeneous thermal dose distribution and improving imaging techniques able to correlate thermal maps of tumors to the clinical outcome of patients (Dewhirst et al., 2010).

\section{NON-INVASIVE IMAGING OF TUMOR OXYGENATION AND PERFUSION}

The study of magnetic resonance (MR) markers over the past decade has provided evidence that the tumor microenvironment and hemodynamics play a major role in determining therapy outcome. Therefore, the identification of relevant non-invasive imaging endpoints is of crucial importance in the management of cancer patients. Improvement of the therapeutic index was evidenced in numerous preclinical studies that used multimodal imaging. The impact of non-invasive imaging in oncology extends from guiding preclinical development of targeted biomarkers and therapeutic agents, to assisting in the diagnosis and staging of tumors in the clinic, as well as monitoring the therapeutic response.

\section{TUMOR OXYGENATION MEASUREMENTS}

There is a critical need for developing dynamic, non-invasive methods for direct oxygen mapping in the clinical practice. Although hypoxia is recognized as a crucial issue in many disorders and in treatment response, the lack of easy-to-use and efficient methods to quantify oxygen deprivation hampers further pathophysiological understanding and restricts the clinical implementation of oxygen mapping techniques resulting in the absence of gold standard for measuring hypoxia in the day-to-day practice (Tatum et al., 2006). Below is a non-exhaustive review of the most relevant non-invasive methods able to assess tumor hemodynamic parameters. Methods to measure absolute $\mathrm{pO}_{2}$ mostly encompass EPR oximetry and 19F relaxometry whereas indirect methods include blood oxygen level dependent (BOLD) MRI, Oxygen enhanced relaxation MRI, Oxygen enhanced longitudinal relaxation MRI, and positron emission tomography (PET) tracers retained in hypoxic regions. Of note, our group has also developed innovative methods to assess tumor oxygen consumption in vitro and in vivo, which have been reviewed elsewhere (Jordan and Gallez, 2011).

\section{Electron paramagnetic resonance oximetry}

Electron paramagnetic resonance is a MR method that detects only species containing unpaired electrons (Gallez and Swartz, 2004). One of the numerous applications of EPR is in vivo oximetry. Molecular oxygen is a triplet radical that possesses two unpaired electrons which are responsible for its paramagnetism. However, EPR is not able to detect oxygen itself when dissolved in fluids near room temperature: in biological systems, the output signal lines are so broadened as to be undetectable. Indirect methods exist. Most of these methods rely on the paramagnetic properties of molecular oxygen, which acts as an efficient relaxer for other paramagnetic species (Gallez et al., 2004). The enhancement of relaxation rates scales linearly with the concentration of oxygen over a wide range of oxygen tensions (typical data are shown in Figure 3). The lack of detectable levels of endogenous paramagnetic species makes it necessary to use exogenous paramagnetic materials. Variations in $\mathrm{pO}_{2}$ of less than $1 \mathrm{mmHg}$ can be detected using particulate materials. While EPR spectroscopy provides local measurements, EPR imaging techniques provide spatially resolved measurements of these materials. The spatial distribution of free radicals can be performed utilizing magnetic field gradients in a manner similar to that of MRI. Spectral-spatial EPR imaging encodes both the spatial distribution of the spin probe and the spectral information, which allows the mapping of molecular oxygen (Kuppusamy et al., 2003). For this purpose, the use of soluble EPR materials such as trityl radicals is more convenient as they can diffuse in the whole tissue.

Electron paramagnetic resonance oximetry was compared with other methods that provide direct or indirect measurements of tumor oxygenation: polarographic electrodes, the distribution of nitroimidazoles, the BOLD effect in MRI, and $\mathrm{pO}_{2}$ recordings using OxyLite (reviewed in Gallez et al., 2004). Two major challenges are now considered for moving this technology into the clinic: (i) assuring biocompatibility of the oxygen sensors in humans and (ii) modifying the instruments so that they can be used for humans instead of small animals (Swartz et al., 2004).

\section{$19 F$ relaxometry}

19F NMR spectroscopy and imaging of perfluorocarbon (PFC) emulsions (hydrocarbons with protons having been replaced with fluorine nuclei) has been extensively exploited to measure the oxygen tension of biological systems in preclinical studies. The $19 \mathrm{~F}$ MR signal of the PFC is sensitive to the $\mathrm{pO}_{2}$ of the surrounding tumor tissue, and acts as an oximeter. The principle behind 


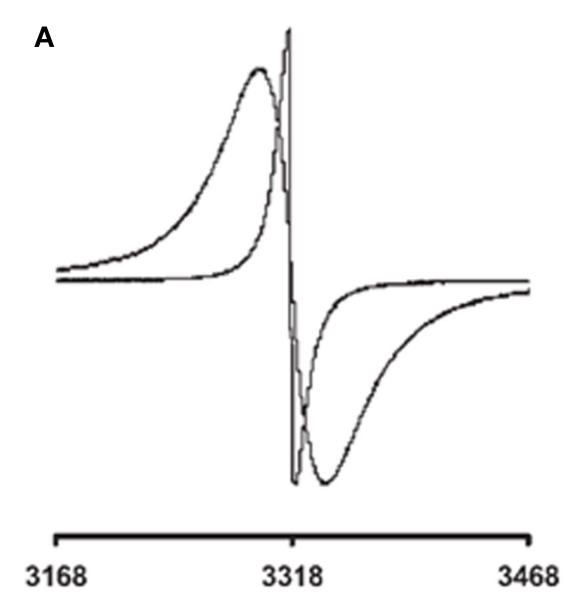

FIGURE 3 | Electron paramagnetic resonance oximetry. Typical sets of EPR data are shown. (A) Effect of oxygen on the EPR spectra of paramagnetic particulate materials: EPR spectra recorded in nitrogen (narrow line) or in air (21\% oxygen, larger linewidth). (B)

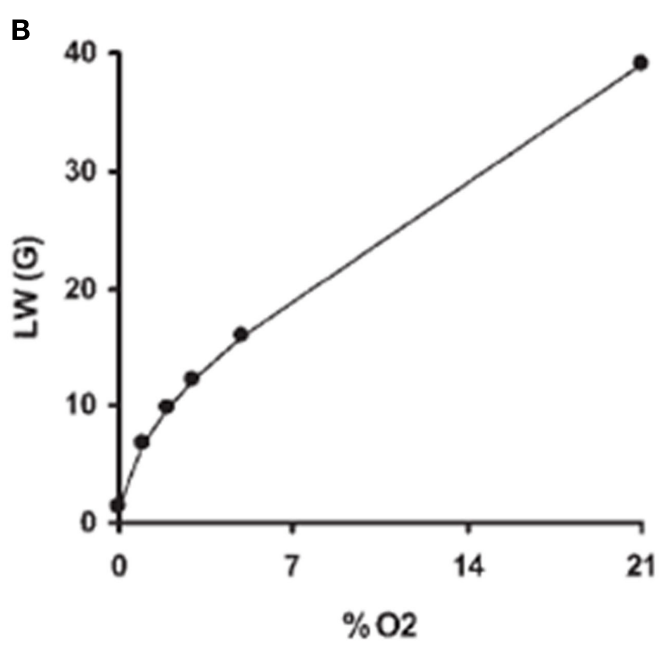

Typical calibration curve (linewidth as a function of the $\mathrm{pO}_{2}$ ) of a charcoal (oxygen sensor probe) possessing a curvilinear response, with a higher sensitivity to oxygen at low $\mathrm{pO}_{2}$. Adapted from Gallez et al. (2004).
19F MR oximetry relies on the linear increase of the NMR spin lattice relaxation rate $R_{1}\left(=1 / T_{1}\right)$ of PFC emulsions with increasing oxygen tension (Mason et al., 1996). 19F MR oximetry provides a sensitive measure of tissue oxygen tension and is a powerful approach for monitoring tumor hypoxia. Several PFCs have been used for NMR oximetry, but hexafluorobenzene (HFB) is preferred (Mason et al., 1996; Zhao et al., 2004) because it has a sixfold symmetry with a single 19F NMR resonance, and a low sensitivity to temperature. Its spin lattice relaxation rate is highly sensitive to $\mathrm{pO}_{2}$ and exhibits a linear relationship across the entire range of tissue oxygenation.

Mason and colleagues have been successfully developing fluorocarbon relaxometry using echo planar imaging for dynamic oxygen mapping (FREDOM) MRI following direct intratumoral injection of the oxygen reporter molecule HFB. Our group further developed an MRI fluorocarbon oximetry technique using snapshot inversion recovery with an improved temporal resolution of $1.5 \mathrm{~min}$ (vs. $6.5 \mathrm{~min}$ for FREDOM; Jordan et al., 2009). Our method therefore provides a rapid way to map tumor oxygenation (typical maps are shown in Figure 4) and is particularly suitable to monitor acute changes of $\mathrm{pO}_{2}$ in tumors, including spontaneous fluctuations (Jordan et al., 2009; Magat et al., 2010). The translation to the clinic is currently limited by the lack of development of coils in the clinical setting, and the lack of characterization of PFCs in humans.

\section{Blood oxygen level dependent MRI}

Functional MRI (fMRI) was first developed as an indirect method of imaging brain activity at high temporal resolution (Ogawa et al., 1990). The relative decrease in deoxyhemoglobin concentration, which has a paramagnetic effect, can be detected by MRI as a weak transient rise in the $T_{2}^{*}$ weighted signal. This is the BOLD contrast principle. Apart from its very large application in neuroscience, the use of BOLD contrast in tumors brought with it new challenges of understanding and interpretation. Since then, BOLD MRI has become a useful tool for addressing important questions regarding the pathophysiology of tumors. However, it has both advantages and disadvantages. One advantage of BOLD MRI is that it is non-invasive and can be used to monitor real time changes of tumor oxygenation during pharmacological treatments or to monitor spontaneous fluctuations in experimental tumors (Baudelet and Gallez, 2002; Baudelet et al., 2004). It does not require externally administered contrast medium or radioactive isotopes, it can be repeated as necessary, and flow dependence can be decoupled. BOLD MRI, in combination with hypercapnia and hyperoxia, is also an attractive method for assessing maturation and the functional state of tumor blood vessels (Baudelet et al., 2006). As for disadvantages, BOLD MRI is unfortunately a non-quantitative method for monitoring tumor $\mathrm{pO}_{2}$. This is the result of the extreme sensitivity of changes in $\mathrm{R}_{2}^{*}$ to the basal state of tumor oxygenation and blood volume fraction. The intra and intertumoral distribution of these parameters may be greatly heterogeneous, making it very difficult to compare estimated $\mathrm{pO}_{2}$ changes between two regions or individuals. Even more problematic is the fact that the change in $\mathrm{R}_{2}^{*}$ is not always indicative of the change in $\mathrm{pO}_{2}$. Concomitant changes in blood volume, blood $\mathrm{pH}$ and metabolic status can lead to smaller-than-expected or even negative changes in $\mathrm{R}_{2}^{*}$ (Baudelet and Gallez, 2002). Similarly, changes in oxygen consumption rate has been described to result in a lack of change in $\mathrm{R}_{2}^{*}$ even though absolute $\mathrm{pO}_{2}$ is increased (Jordan et al., 2006b).

\section{Oxygen enhanced longitudinal relaxation MRI}

An alternative MRI technique for evaluating change in tumor oxygenation using endogenous contrast relies in the increase of the proton longitudinal relaxation rate $\left(R_{1}\right)$ of water containing oxygen, due to the paramagnetic properties of oxygen. The measured change in $R_{1}$ is, in theory, proportional to the change in tissue 


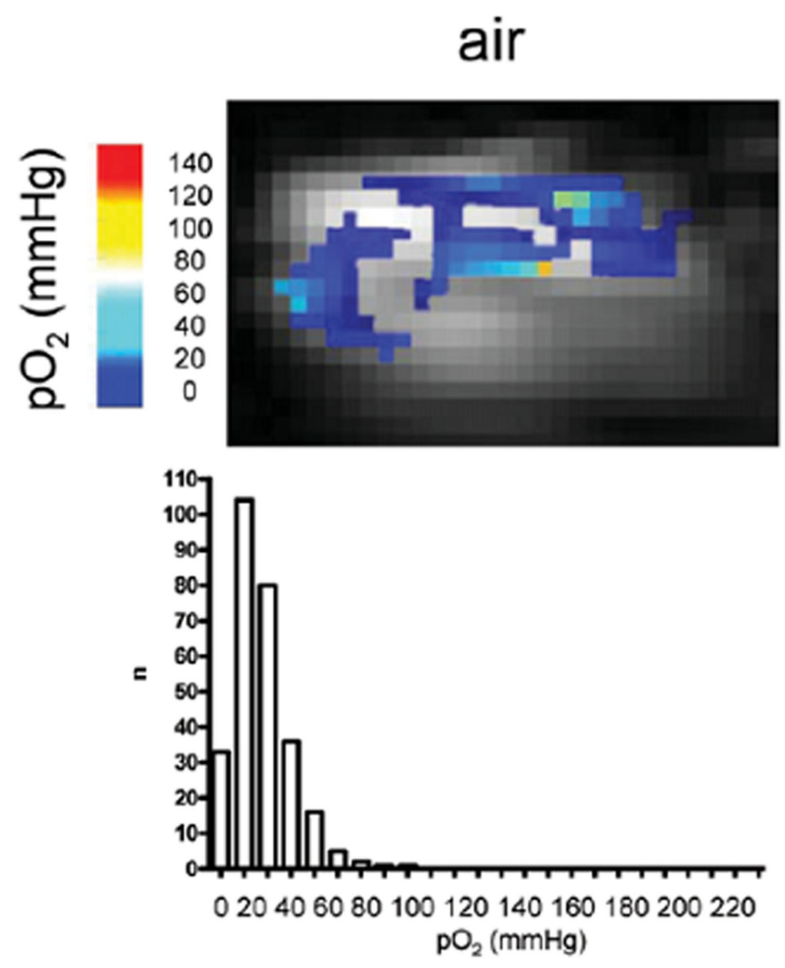

\section{carbogen}
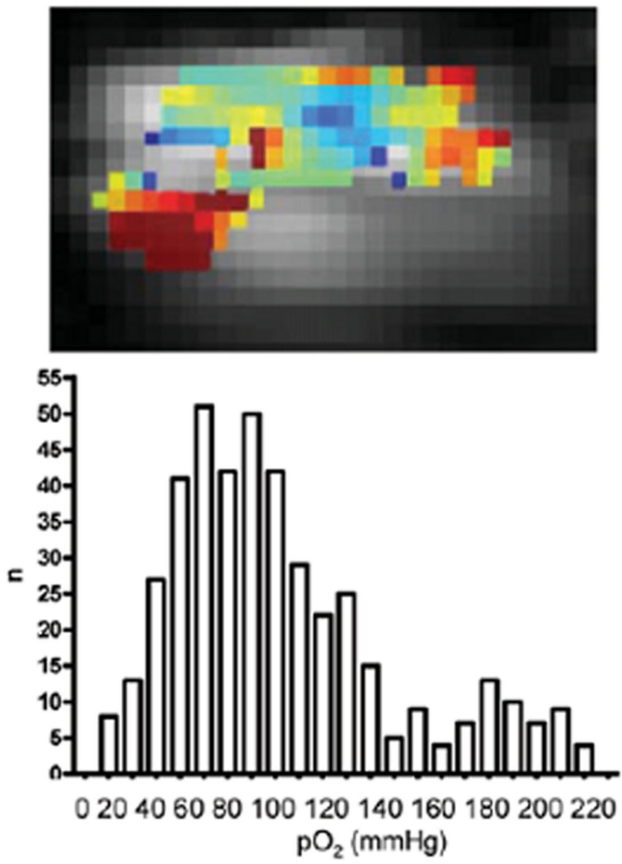

FIGURE 4 | 19F-MRI oxygen mapping. Shown are typical oxygen maps obtained using 19F-MRI with hexafluorobenzene as the oxygen sensor in an experimental tumor under air or carbogen $\left(95 \% \mathrm{O}_{2}, 5 \% \mathrm{CO}_{2}\right)$ breathing conditions. The corresponding histograms are shown, in which " $n$ " represents the number of voxels for a given oxygen concentration range. Adapted from reference Jordan et al. (2009). oxygen concentration (O'Connor et al., 2007, 2009). Studies have indeed demonstrated that oxygen enhanced MRI produces measurable signal changes in normal tissues in patients and is feasible on conventional clinical scanners. Therefore, oxygen-induced increase in $R_{1}$ has the potential to provide non-invasive measurements of change in tumor oxygen concentration, distinct from BOLD imaging. Nevertheless, the technique still lacks in sensitivity and the measured delta $R_{1}$ may include errors resulting from changes independent of tissue oxygen content, such as alteration in blood flow or tissue $\mathrm{H}_{2} \mathrm{O}$ content (O'Connor et al., 2009).

\section{Hypoxia assessed by positron emission tomography}

$18 \mathrm{~F}$ labeled fluoromisonidazole (18F-MISO) is probably the most widely used PET imaging agent for hypoxia. 18F-MISO accumulates in tissues by binding to intracellular macromolecules when $\mathrm{pO}_{2}<10 \mathrm{mmHg}$. Retention within tissues is dependent on nitroreductase activity (that is, on the reduction status of a $\mathrm{NO}_{2}$ group on the imidazole ring) and accumulation in hypoxic tissues over a range of blood flows has been observed (Tatum et al., 2006). $18 \mathrm{~F}-\mathrm{MISO}$ is only sensitive to the presence of hypoxia in viable cells: $18 \mathrm{~F}-\mathrm{MISO}$ is not retained in necrosis because the electron transport chain that reduces the nitroimidazole to a bioreductive alkylating agent is no longer active (Padhani et al., 2007). Nevertheless, 18F-MISO PET is able to monitor the changing hypoxia status of lung tumors during radiotherapy (Koh et al., 1995). Studies in sarcoma (Rajendran et al., 2003) and head and neck cancer (Rajendran et al., 2006) have demonstrated a correlation of 18F-MISO uptake with poor outcome to radiation and chemotherapy. Other 18F labeled nitroimidazoles are currently evaluated, including EF3 and fluoroazomycin arabinoside (FAZA), for example (Tatum et al., 2006).

\section{TUMOR PERFUSION MEASUREMENTS}

Microvascular parameters such as permeability and perfusion are of particular interest in the context of the abnormal tumor microvascular network. Useful imaging systems have been developed to monitor angiogenesis and the microvasculature in vivo, including DCE-MRI, (Choyke et al., 2003) PET, and single photon emission computed tomography (SPECT), CT, Doppler ultrasound, and optical imaging methods (see Jennings et al., 2008).

\section{Dynamic contrast-enhanced MRI}

Dynamic contrast-enhanced magnetic resonance imaging consists in the acquisition of serial MR images before, during, and after the administration of an intravenous contrast agent (CA) to produce time series images that enable pixel-by-pixel analysis of contrast kinetics within a tumor. Pharmacokinetic models provide a means of summarizing contrast enhancement data in terms of parameters that relate to the underlying vascular anatomy and physiology. As described by Tofts et al. (1999) the essential features of a variety of models are covered by the generalized kinetic model. Most methods of analyzing dynamic contrast-enhanced $T_{1}$-weighted data acquired with low molecular contrast medium use a compartmental analysis to obtain some combination of the three principal 
parameters: the transfer constant Ktrans in $\min ^{-1}$ (volume transfer constant between blood plasma and extravascular extracellular space, EES), the rate constant Kep in $\operatorname{~min}^{-1}$ (rate constant between blood plasma and EES), and the volume of EES per unit volume of tissue space, $\mathrm{Vp}$ (no unit). DCE-MRI has evolved from an experimental technique to a clinically feasible adjunct procedure that can be integrated into a standard morphologic imaging protocol. It does provide unique non-invasive functional information on the properties of tumors related to microcirculation (distribution volume, permeability, and perfusion). This information can improve diagnostic characterization, the follow-up of therapy, and tumor staging; and it provides tools to facilitate advanced molecular imaging. Preclinical and clinical studies suggest that a successful antivascular treatment results in a decrease in the rate of enhancement along with a decreased amplitude and a slower washout, and that poor response can result in persistent abnormal enhancement (Gillies et al., 2002).

\section{Positron emission tomography}

Generally, PET measures of tumor perfusion have used (15O)labeled radiotracers. The so-called steady state method requires inhalation of $15 \mathrm{O}-\mathrm{CO}_{2}$ and the dynamic method requires an intravenous bolus injection of $15 \mathrm{O}-\mathrm{H}_{2} \mathrm{O}$ (Jennings et al., 2008). A requirement for quantification of perfusion using dynamic methods is an accurate determination of an arterial input function, which can be obtained non-invasively in a purely arterial region of interest, such as the aorta.

\section{Computed tomography}

In X-ray CT, the tissue contrast is based on variable attenuation coefficients of the object absorbing the X-rays. Hemodynamic parameters may be extracted from dynamic changes in X-ray attenuation caused by the intravenous injection of an iodinated contract agent. Perfusion CT data can deliver quantitative hemodynamic information, such as blood volume, blood flow, permeability surface-area product and mean transit time (MTT; Jennings et al., 2008).

\section{Doppler ultrasound}

There are several different ultrasonic approaches designed specifically to measure blood flow including transit time, continuouswave Doppler, pulsed and color Doppler, and power Doppler flowmeters, requiring the use of microbubbles (filled with air, perfluorocarbon, sulfur hexafluoride, or nitrogen), which expand and contract because of pressure from the acoustical transmit pulse, and the primary mode of echogenicity is the impedance mismatch between the microbubble-blood interface, making them significantly more echogenic than normal tissue. Typical parameters that are estimated using Doppler ultrasound include: percent intratumor CA uptake, enhancement timing and pattern, percent blood volume fraction, red blood cell velocity, and perfusion; depending on the type of study and tracer used (Jennings et al., 2008).

\section{CONCLUSION}

Heterogeneities in blood flow and oxygenation are key characteristics of solid tumors and constitute a therapeutic challenge when these tumors are treated with radiotherapy or systemic therapies. Because oxygen stabilizes DNA lesions, tumors become increasingly resistant to radiotherapy and to several forms of chemotherapy when the tumor $\mathrm{pO}_{2}$ decreases below a threshold of $10 \mathrm{mmHg}$. In the past decades, basic and preclinical researches have identified several adjuvant treatments aimed at transiently increasing tumor oxygenation at the time of radiotherapy. Their identification was based on an increasing understanding of the origins of tumor hypoxia, which logically opened two main avenues: co-treatments designed to (1) improve the oxygen supply from blood vessels at the time of radiotherapy (with different strategies such as increasing the $\mathrm{O}_{2}$ content of blood, inducing tumor-specific vasodilation, or normalizing vascular structures), and (2) reduce the rate of $\mathrm{O}_{2}$ consumption by tumor cells through metabolic interventions. Theoretical models now validated preclinically have revealed that the metabolic strategy has the highest impact on tumor radiosensitivity, but the best opportunity still resides in treatments combining both vascular and metabolic effects (Table 1), as perfectly illustrated with hyperthermia. Most systemic anticancer treatments are also confronted to the difficulty to reach a target often located at distance from blood vessels, thus indicating that in this case increased tumor perfusion (i.e., decreased resistance to flow) could improve tumor bioavailability. NO donors, ET-1 inhibitors, radiotherapy or heat as adjuvant provascular treatments, or anti-angiogenic therapies and chemotherapy used in a "vascular normalization" mode, have all demonstrated their capacity to chemosensitize tumors in preclinical settings. Most of the adjuvant treatments described here could theoretically be exploited therapeutically by the off-label use of existing FDAapproved drugs, but it has also become evident that a given tumor in a given patient would respond differently than the tumor of the patient next-door. It is therefore urgent to develop and implement in the clinics imaging techniques able not only to provide predictive markers but also biological markers of the response to such combinational interventions. The MR and PET techniques that we reviewed here are among the most-sensitive non-invasive techniques having proved their highly valuable power as to measure changes in tumor perfusion and oxygenation preclinically. Current challenges include the FDA approval of exogenous tracers and sensors when needed, scaling-up tools initially dedicated for small laboratory animals and adapting imaging protocols to the clinical situation, the transfer to the clinics of the expertise needed for protocol design and data interpretation and, as importantly, a careful consideration of societal cost issues.

\section{ACKNOWLEDGMENTS}

Works at the authors' labs are supported by grants from the European Research Council (FP7/2007-2013 ERC Independent Researcher Starting Grant 243188 TUMETABO to Pierre Sonveaux), the Belgian Fonds National de la Recherche Scientifique (F.R.S.-FNRS), the Communauté Française de Belgique (ARC 09/14-020), the Fondation Belge Contre le Cancer (200-2008), the Fonds Joseph Maisin, the Saint-Luc Foundation, and the Pôle d'Attraction Interuniversitaire PAI VI (P6/38). Bénédicte F. Jordan and Pierre Sonveaux are F.R.S.-FNRS Research Associates. Dedicated to the loving memory of Mrs Anne-Sophie Brouckaert, PharmD. 


\section{REFERENCES}

Ang, K. K. (2010). More lessons learned from the suffocation of hypoxia. $J$. Clin. Oncol. 28, 2941-2943.

Angelo, M., Singel, D. J., and Stamler, J. S. (2006). An S-nitrosothiol (SNO) synthase function of hemoglobin that utilizes nitrite as a substrate. Proc. Natl. Acad. Sci. U.S.A. 103, 8366-8371.

Ansiaux, R., Baudelet, C., Jordan, B. F., Beghein, N., Sonveaux, P., De Wever, J., Martinive, P., Gregoire, V., Feron, O., and Gallez, B. (2005). Thalidomide radiosensitizes tumors through early changes in the tumor microenvironment. Clin. Cancer Res. 11, 743-750.

Ansiaux, R., Baudelet, C., Jordan, B. F., Crokart, N., Martinive, P., DeWever, J., Gregoire, V., Feron, O., and Gallez, B. (2006). Mechanism of reoxygenation after antiangiogenic therapy using SU5416 and its importance for guiding combined antitumor therapy. Cancer Res. 66, 9698-9704.

Ansiaux, R., DeWever, J., Gregoire, V., Feron, O., Jordan, B. F., and Gallez, B. (2009). Decrease in tumor cell oxygen consumption after treatment with vandetanib (ZACTIMA; ZD6474) and its effect on response to radiotherapy. Radiat. Res. 172, 584-591.

Arnold, W. P., Mittal, C. K., Katsuki, S., and Murad, F. (1977). Nitric oxide activates guanylate cyclase and increases guanosine 3':5'-cyclic monophosphate levels in various tissue preparations. Proc. Natl. Acad. Sci. U.S.A. 74, 3203-3207.

Baudelet, C., Ansiaux, R., Jordan, B. F., Havaux, X., Macq, B., and Gallez, B. (2004). Physiological noise in murine solid tumours using $\mathrm{T}_{2}^{*}$ weighted gradient-echo imaging: a marker of tumour acute hypoxia? Phys. Med. Biol. 49, 3389-3411.

Baudelet, C., Cron, G. O., Ansiaux, R., Crokart, N., DeWever, J., Feron, O., and Gallez, B. (2006). The role of vessel maturation and vessel functionality in spontaneous fluctuations of $\mathrm{T}_{2}^{*}$-weighted GRE signal within tumors. NMR Biomed. 19, 69-76.

Baudelet, C., and Gallez, B. (2002). How does blood oxygen level-dependent (BOLD) contrast correlate with oxygen partial pressure ( $\mathrm{pO} 2)$ inside tumors? Magn. Reson. Med. 48, 980-986.

Biaglow, J. E., Manevich, Y., Leeper, D., Chance, B., Dewhirst, M. W., Jenkins, W. T., Tuttle, S. W., Wroblewski, K., Glickson, J. D., Stevens, C., and Evans, S. M. (1998). MIBG inhibits respiration: potential for radio- and hyperthermic sensitization. Int. J. Radiat. Oncol. Biol. Phys. 42, 871-876.

Boucher, Y., Leunig, M., and Jain, R. K. (1996). Tumor angiogenesis and interstitial hypertension. Cancer Res. 56, 4264-4266.

Bradley, D. P., Tessier, J. L., Checkley, D., Kuribayashi, H., Waterton, J. C., Kendrew, J., and Wedge, S. R. (2008). Effects of AZD2171 and vandetanib (ZD6474, Zactima) on haemodynamic variables in an SW620 human colon tumour model: an investigation using dynamic contrastenhanced MRI and the rapid clearance blood pool contrast agent, P792 (gadomelitol). NMR Biomed. 21, 42-52.

Brizel, D. M., Scully, S. P., Harrelson, J. M., Layfield, L. J., Dodge, R. K., Charles, H. C., Samulski, T. V., Prosnitz, L. R., and Dewhirst, M. W. (1996). Radiation therapy and hyperthermia improve the oxygenation of human soft tissue sarcomas. Cancer Res. 56, 5347-5350.

Cardenas-Navia, L. I., Mace, D., Richardson, R. A., Wilson, D. F., Shan, S., and Dewhirst, M. W. (2008). The pervasive presence of fluctuating oxygenation in tumors. Cancer Res. 68, 5812-5819.

Choyke, P. L., Dwyer, A. J., and Knopp, M. V. (2003). Functional tumor imaging with dynamic contrastenhanced magnetic resonance imaging. J. Magn. Reson. Imaging 17, 509-520.

Claes, A., Wesseling, P., Jeuken, J., Maass, C., Heerschap, A., and Leenders, W. P. (2008). Antiangiogenic compounds interfere with chemotherapy of brain tumors due to vessel normalization. Mol. Cancer Ther. 7, 71-78.

Cristofanilli, M., Yamamura, Y., Kau, S. W., Bevers, T., Strom, S., Patangan, M., Hsu, L., Krishnamurthy, S., Theriault, R. L., and Hortobagyi, G. N. (2005). Thyroid hormone and breast carcinoma. Primary hypothyroidism is associated with a reduced incidence of primary breast carcinoma. Cancer 103, 1122-1128.

Crokart, N., Jordan, B. F., Baudelet, C., Cron, G. O., Hotton, J., Radermacher, K., Gregoire, V., Beghein, N., Martinive, P., Bouzin, C., Feron, O., and Gallez, B. (2007). Glucocorticoids modulate tumor radiation response through a decrease in tumor oxygen consumption. Clin. Cancer Res. 13, 630-635.

Crokart, N., Radermacher, K., Jordan, B. F., Baudelet, C., Cron, G. O., Gregoire, V., Beghein, N. Bouzin, C., Feron, O., and Gallez,
B. (2005a). Tumor radiosensitization by antiinflammatory drugs: evidence for a new mechanism involving the oxygen effect. Cancer Res. 65, 7911-7916.

Crokart, N., Jordan, B. F., Baudelet, C., Ansiaux, R., Sonveaux, P., Grégoire, V., Beghein, N., DeWever, J., Bouzin, C., Feron, O., and Gallez, B. (2005b). Early reoxygenation in tumors after irradiation: determining factors and consequences for radiotherapy regimens using daily multiple fractions. Int. J. Radiat. Oncol. Biol. Phys. 63, 901-910.

Dewhirst, M. W., Kimura, H., Rehmus, S. W., Braun, R. D., Papahadjopoulos, D., Hong, K., and Secomb, T. W. (1996). Microvascular studies on the origins of perfusion-limited hypoxia. Br. J. Cancer Suppl. 27 S247-S251.

Dewhirst, M. W., Ong, E. T., Braun, R. D., Smith, B., Klitzman, B. Evans, S. M., and Wilson, D. (1999). Quantification of longitudinal tissue $\mathrm{pO}_{2}$ gradients in window chamber tumours: impact on tumour hypoxia. Br. J. Cancer 79, 1717-1722.

Dewhirst, M. W., Thrall, D. E., Palmer G., Schroeder, T., Vujaskovic, Z., Cecil, C. H., Macfall, J., and Wong, T. (2010). Utility of functional imaging in prediction or assessment of treatment response and prognosis following thermotherapy. Int. J. Hyperthermia 26, 283-293.

Feron, O. (2004). Targeting the tumor vascular compartment to improve conventional cancer therapy. Trends Pharmacol. Sci. 25, 536-542.

Folkman, J., Browder, T., and Palmblad, J. (2001). Angiogenesis research: guidelines for translation to clinical application. Thromb. Haemost. 86, 23-33.

Frerart, F., Sonveaux, P., Rath, G., Smoos, A., Meqor, A., Charlier, N., Jordan, B. F., Saliez, J., Noel, A., Dessy, C., Gallez, B., and Feron, O. (2008). The acidic tumor microenvironment promotes the reconversion of nitrite into nitric oxide: towards a new and safe radiosensitizing strategy. Clin. Cancer Res. 14, 2768-2774.

Gallez, B., Baudelet, C., and Jordan, B. F. (2004). Assessment of tumor oxygenation by electron paramagnetic resonance: principles and applications. NMR Biomed. 17, 240-262.

Gallez, B., and Swartz, H. M. (2004). In vivo EPR: when, how and why? NMR Biomed. 17, 223-225.

Gatenby, R. A., Kessler, H. B., Rosenblum, J. S., Coia, L. R., Moldofsky, P. J., Hartz, W. H., and Broder, G. J. (1988). Oxygen distribution in squamous cell carcinoma metastases and its relationship to outcome of radiation therapy. Int. J. Radiat. Oncol. Biol. Phys. 14, 831-838.

Gillies, R. J., Raghunand, N., Karczmar, G. S., and Bhujwalla, Z. M. (2002). MRI of the tumor microenvironment. J. Magn. Reson. Imag. 16, 430-450.

Godber, B. L., Doel, J. J., Sapkota, G. P., Blake, D. R., Stevens, C. R., Eisenthal, R., and Harrison, R. (2000). Reduction of nitrite to nitric oxide catalyzed by xanthine oxidoreductase. J. Biol. Chem. 275, 7757-7763.

Gray, L. H., Conger, A. D., Ebert, M., Hornsey, S., and Scott, O. C. (1953). The concentration of oxygen dissolved in tissues at the time of irradiation as a factor in radiotherapy. $\mathrm{Br}$. J. Radiol. 26, 638-648.

Gredilla, R., Lopez, T. M., PorteroOtin, M., Pamplona, R., and Barja, G. (2001). Influence of hyper- and hypothyroidism on lipid peroxidation, unsaturation of phospholipids, glutathione system and oxidative damage to nuclear and mitochondrial DNA in mice skeletal muscle. $\mathrm{Mol}$. Cell. Biochem. 221, 41-48.

Haynes, W. G., and Webb, D. J. (1994). Contribution of endogenous generation of endothelin-1 to basal vascular tone. Lancet. 344, 852-854.

Hercbergs, A., and Leith, J. T. (1993). Spontaneous remission of metastatic lung cancer following myxedema coma - an apoptosis-related phenomenon? J. Natl. Cancer Inst. 85, 1342-1343.

Hercbergs, A. A., Goyal, L. K., Suh, J. H., Lee, S., Reddy, C. A., Cohen, B. H., Stevens, G. H., Reddy, S. K., Peereboom, D. M., Elson, P. J., Gupta, M. K., and Barnett, G. H. (2003). Propylthiouracil-induced chemical hypothyroidism with highdose tamoxifen prolongs survival in recurrent high grade glioma: a phase I/II study. Anticancer Res. 23, 617-626.

Hockel, M., Vorndran, B., Schlenger, K., Baussmann, E., and Knapstein, P. G. (1993). Tumor oxygenation: a new predictive parameter in locally advanced cancer of the uterine cervix. Gynecol. Oncol. 51, 141-149.

Holland, M. A., and Kozlowski, L. M. (1986). Clinical features and management of cyanide poisoning. Clin. Pharm. 5, 737-741.

Horsman, M. R., and van der Kogel, A. J. (2009). "Therapeutic approaches to tumor hypoxia," in Basic Clinical Radiobiology, 4th Edn, eds M. Joiner and A. J. van der Kogel (London: H. Arnold), 233-245.

Hoskin, P., Rojas, A., Bentzen, S., and Saunders, M. (2009). "Randomised 
phase III trial of radiotherapy with concurrent carbogen and nicotinamide in locally advanced bladder cancer," in Conference Proceedings ASTRO, Chicago.

Huang, A., and Koller, A. (1997). Endothelin and prostaglandin $\mathrm{h}_{2}$ enhance arteriolar myogenic tone in hypertension. Hypertension 30, 1210-1215.

Jain, R. K. (2001). Normalizing tumor vasculature with anti-angiogenic therapy: a new paradigm for combination therapy. Nat. Med. 7, 987-989.

Jennings, D., Raghunand, N., and Gillies, R. J. (2008). Imaging hemodynamics. Cancer Metastasis Rev. 27, 589-613.

Jia, L., Bonaventura, C., Bonaventura, J., and Stamler, J. S. (1996). S-nitrosohaemoglobin: a dynamic activity of blood involved in vascular control. Nature 380, 221-226.

Jones, E. L., Oleson, J. R., Prosnitz, L. R., Samulski, T. V., Vujaskovic, Z., Yu, D., Sanders, L. L., and Dewhirst, M. W. (2005). Randomized trial of hyperthermia and radiation for superficial tumors. J. Clin. Oncol. 23, 3079-3085.

Jones, E. L., Samulski, T. V., Dewhirst, M. W., Alvarez-Secord, A., Berchuck, A., Clarke-Pearson, D., Havrilesky, L. J., Soper, J., and Prosnitz, L. R. (2003). A pilot phase II trial of concurrent radiotherapy, chemotherapy, and hyperthermia for locally advanced cervical carcinoma. Cancer 98, 277-282.

Jordan, B. F., Beghein, N., Crokart, N., Baudelet, C., Gregoire, V., and Gallez, B. (2006a). Preclinical safety and antitumor efficacy of insulin combined with irradiation. Radiother. Oncol. 81, 112-117.

Jordan, B. F., Crokart, N., Baudelet, C., Cron, G. O., Ansiaux, R., and Gallez, B. (2006b). Complex relationship between changes in oxygenation status and changes in $\mathrm{R}^{*} 2$ : the case of insulin and NS-398, two inhibitors of oxygen consumption. Magn. Reson. Med. 56, 637-643.

Jordan, B. F., Christian, N., Crokart, N., Gregoire, V., Feron, O., and Gallez, B. (2007). Thyroid status is a key modulator of tumor oxygenation: implication for radiation therapy. Radiat. Res. 168, 428-432.

Jordan, B. F., Cron, G. O., and Gallez, B. (2009). Rapid monitoring of oxygenation by $19 \mathrm{~F}$ magnetic resonance imaging: simultaneous comparison with fluorescence quenching. Magn. Reson. Med. 61, 634-638.

Jordan, B. F., and Gallez, B. (2010). Surrogate MR markers of response to chemo- or radiotherapy in association with co-treatments: a retrospective analysis of multi-modal studies. Contrast Media Mol. Imaging 5, 323-332.

Jordan, B. F., and Gallez, B. (2011). "Non-invasive imaging of the tumor microenvironment," in Tumor Microenvirnment, ed. D. W. Siemann (Oxford: John Wiley \& Sons Inc.), 229-270.

Jordan, B. F., Gregoire, V., Demeure, R. J., Sonveaux, P., Feron, O., O'Hara, J., Vanhulle, V. P., Delzenne, N., and Gallez, B. (2002). Insulin increases the sensitivity of tumors to irradiation: involvement of an increase in tumor oxygenation mediated by a nitric oxide-dependent decrease of the tumor cells oxygen consumption. Cancer Res. 62, 3555-3561.

Jordan, B. F., Misson, P., Demeure, R., Baudelet, C., Beghein, N., and Gallez, B. (2000). Changes in tumor oxygenation/perfusion induced by the no donor, isosorbide dinitrate, in comparison with carbogen: monitoring by EPR and MRI. Int. J. Radiat. Oncol. Biol. Phys. 48, 565-570.

Jordan, B. F., Peeterbroeck, J., Karroum, O., Diepart, C., Magat, J., Gregoire, V., and Gallez, B. (2010). Captopril and S-nitrosocaptopril as potent radiosensitizers: comparative study and underlying mechanisms. Cancer Lett. 293, 213-219.

Jordan, B. F., Sonveaux, P., Feron, O., Gregoire, V., Beghein, N., Dessy, C., and Gallez, B. (2004). Nitric oxide as a radiosensitizer: evidence for an intrinsic role in addition to its effect on oxygen delivery and consumption. Int. J. Cancer 109, 768-773.

Kaanders, J. H., Bussink, J., and van der Kogel, A. J. (2002). ARCON: a novel biology-based approach in radiotherapy. Lancet Oncol. 3, 728-737.

Kelleher, D. K., Engel, T., and Vaupel, P. W. (1995). Changes in microregional perfusion, oxygenation, ATP and lactate distribution in subcutaneous rat tumours upon water-filtered IR-A hyperthermia. Int. J. Hyperthermia 11, 241-255.

Kimberg, D. V., Loud, A. V., and Wiener, J. (1968). Cortisone-induced alterations in mitochondrial function and structure. J. Cell Biol. 37, 63-79.

Kimura, H., Braun, R. D., Ong, E. T., Hsu, R., Secomb, T. W., Papahadjopoulos, D., Hong, K., and Dewhirst, M. W. (1996). Fluctuations in red cell flux in tumor microvessels can lead to transient hypoxia and reoxygenation in tumor parenchyma. Cancer Res. 56, 5522-5528.
Koh, W. J., Bergman, K. S., Rasey, J. S., Peterson, L. M., Evans, M. L., Graham, M. M., Grierson, J. R., Lindsley, K. L., Lewellen, T. K. and Krohn, K. A. (1995). Evaluation of oxygenation status during fractionated radiotherapy in human nonsmall cell lung cancers using [F-18]fluoromisonidazole positron emission tomography. Int. J. Radiat. Oncol. Biol. Phys. 33, 391-398.

Kuppusamy, P., Chzhan, M., and Zweier J. L. (2003). "Principles of imaging in vivo EPR (ESR)," in Theory and Applications: Biological Magnetic Resonance, Vol. 18, ed. L. J. Berliner (New York: Kluwer Academic/Plenum), 99-152.

Lepock, J. R., Cheng, K. H., Al Qysi, H., Sim, I., Koch, C. J., and Kruuv, J. (1987). Hyperthermia-induced inhibition of respiration and mitochondrial protein denaturation in CHL cells. Int. J. Hyperthermia 3, 123-132.

Magat, J., Jordan, B. F., Cron, G. O., and Gallez, B. (2010). Noninvasive mapping of spontaneous fluctuations in tumor oxygenation using ${ }^{19} \mathrm{~F}$ MRI. Med. Phys. 37, 5434-5441.

Maguire, J. J., and Davenport, A. P. (1995). ETA receptor-mediated constrictor responses to endothelin peptides in human blood vessels in vitro. Br. J. Pharm. 115, 191-197.

Martinive, P., De Wever, J., Bouzin C., Baudelet, C., Sonveaux, P., Gregoire, V., Gallez, B., and Feron, O. (2006). Reversal of temporal and spatial heterogeneities in tumor perfusion identifies the tumor vascular tone as a tunable variable to improve drug delivery. Mol. Cancer Ther. 5, 1620-1627.

Mason, R. P., Rodbumrung, W., and Antich, P. P. (1996). Hexafluorobenzene: a sensitive 19F NMR indicator of tumor oxygenation. NMR Biomed. 9, 125-134.

Mattson, J., Appelgren, L., Karlsson, L., and Peterson, H. I. (1978) Influence of vasoactive drugs and ischaemia on intra-tumour blood flow distribution. Eur. J. Cancer 14 761-764.

McDonald, D. M., and Baluk, P. (2002). Significance of blood vessel leakiness in cancer. Cancer Res. 62, 5381-5385.

McMahon, T. J., Moon, R. E., Luschinger, B. P., Carraway, M. S., Stone, A. E., Stolp, B. W., Gow, A. J., Pawloski, J. R., Watke, P., Singel, D. J., Piantadosi, C. A., and Stamler, J. S. (2002). Nitric oxide in the human respiratory cycle. Nat. Med. 8, 711-717.

Michel, J. B., Feron, O., Sase, K., Prabhakar, P., and Michel, T. (1997).
Caveolin versus calmodulin. Counterbalancing allosteric modulators of endothelial nitric oxide synthase. J. Biol. Chem. 272, 25907-25912.

Mishkin, S. Y., Pollack, R., Yalovsky, M. A., Morris, H. P., and Mishkin, S. (1981). Inhibition of local and metastatic hepatoma growth and prolongation of survival after induction of hypothyroidism. Cancer Res. 41, 3040-3045.

Modin, A., Bjorne, H., Herulf, M., Alving, K., Weitzberg, E., and Lundberg, J. O. (2001). Nitrite-derived nitric oxide: a possible mediator of "acidicmetabolic" vasodilation. Acta Physiol. Scand. 171, 9-16.

Moon, E. J., Sonveaux, P., Porporato, P. E., Danhier, P., Gallez, B., BatinicHaberle, I., Nien, Y. C., Schroeder, T., and Dewhirst, M. W. (2010). $\mathrm{NADPH}$ oxidase-mediated reactive oxygen species production activates hypoxia-inducible factor-1 (HIF-1) via the ERK pathway after hyperthermia treatment. Proc. Natl. Acad. Sci. U.S.A. 107, 20477-20482.

Moya, M. P., Gow, A. J., Califf, R. M., Goldberg, R. N., and Stamler, J. S. (2002). Inhaled ethyl nitrite gas for persistent pulmonary hypertension of the newborn. Lancet 360, 141-143.

Munn, L. L. (2003). Aberrant vascular architecture in tumors and its importance in drug-based therapies. Drug Discov. Today 8, 396-403.

O'Connor, J. P., Jackson, A., Buonaccorsi, G. A., Buckley, D. L., Roberts, C., Watson, Y., Cheung, S., McGrath, D. M., Naish, J. H., Rose, C. J., Dark, P. M., Jayson, G. C., and Parker, G. J. (2007). Organ-specific effects of oxygen and carbogen gas inhalation on tissue longitudinal relaxation times. Magn. Reson. Med. 58, 490-496.

O’Connor, J. P., Naish, J. H., Jackson, A., Waterton, J. C., Watson, Y., Cheung, S., Buckley, D. L., McGrath, D. M., Buonaccorsi, G. A., Mills, S. J., Roberts, C., Jayson, G. C., and Parker, G. J. (2009). Comparison of normal tissue $\mathrm{R} 1$ and $\mathrm{R}^{*} 2$ modulation by oxygen and carbogen. Magn. Reson. Med. 61, 75-83.

Ogawa, S., Lee, T. M., Kay, A. R., and Tank, D. W. (1990). Brain magnetic resonance imaging with contrast dependent on blood oxygenation. Proc. Natl. Acad. Sci. U.S.A. 87, 9868-9872.

Okunieff, P., Hoeckel, M., Dunphy, E. P., Schlenger, K., Knoop, C., and Vaupel, P. (1993). Oxygen tension distributions are sufficient to explain the local response of human breast tumors treated with radiation alone. 
Int. J. Radiat. Oncol. Biol. Phys. 26, 631-636.

Overgaard, J. (2007). Hypoxic radiosensitization: adored and ignored. J. Clin. Oncol. 25, 4066-4074.

Overgaard, J., Hansen, H. S., Overgaard, M., Bastholt, L., Berthelsen, A., Specht, L., Lindelov, B., and Jorgensen, K. (1998). A randomized double-blind phase III study of nimorazole as a hypoxic radiosensitizer of primary radiotherapy in supraglottic larynx and pharynx carcinoma. Results of the Danish Head and Neck Cancer Study (DAHANCA) Protocol 5-85. Radiother. Oncol. 46, 135-146.

Padhani, A. R., Krohn, K. A., Lewis, J. S., and Alber, M. (2007). Imaging oxygenation of human tumours. Eur. Radiol. 17, 861-872.

Patan, S., Munn, L. L., and Jain, R. K. (1996). Intussusceptive microvascular growth in a human colon adenocarcinoma xenograft: a novel mechanism of tumor angiogenesis. Microvasc. Res. 51, 260-272.

Peters, L. J., O’Sullivan, B., Giralt, J., Fitzgerald, T. J., Trotti, A., Bernier, J., Bourhis, J., Yuen, K., Fisher, R., and Rischin, D. (2010). Critical impact of radiotherapy protocol compliance and quality in the treatment of advanced head and neck cancer: results from TROG 02.02. J. Clin. Oncol. 28, 2996-3001.

Peterson, H. I., and Mattson, J. (1984). Vasoactive drugs and tumor blood flow. Biorheology 21, 503-508.

Pilkington, G. J., Parker, K., and Murray, S. A. (2008). Approaches to mitochondrially mediated cancer therapy. Semin. Cancer Biol. 18, 226-235.

Rajendran, J. G., Schwartz, D. L., O'Sullivan, J., Peterson, L. M., Ng, P., Scharnhorst, J., Grierson, J. R., and Krohn, K. A. (2006). Tumor hypoxia imaging with [F-18] fluoromisonidazole positron emission tomography in head and neck cancer. Clin. Cancer Res. 12, 5435-5441.

Rajendran, J. G., Wilson, D. C., Conrad, E. U., Peterson, L. M., Bruckner, J. D., Rasey, J. S., Chin, L. K., Hofstrand, P. D., Grierson, J. R., Eary, J. F., and Krohn, K. A. (2003). [(18)F]FMISO and [(18)F]FDG PET imaging in soft tissue sarcomas: correlation of hypoxia, metabolism and VEGF expression. Eur. J. Nucl. Med. Mol. Imaging 30, 695-704.

Rischin, D., Peters, L., Fisher, R., Macann, A., Denham, J., Poulsen, M., Jackson, M., Kenny, L., Penniment, M., Corry, J., Lamb, D., and McClure, B. (2005). Tirapazamine, cisplatin, and radiation versus fluorouracil, cisplatin, and radiation in patients with locally advanced head and neck cancer: a randomized phase II trial of the TransTasman Radiation Oncology Group (TROG 98.02). J. Clin. Oncol. 23, 79-87.

Rischin, D., Peters, L., Hicks, R., Hughes, P., Fisher, R., Hart, R., Sexton, M., D'Costa, I., and von Roemeling, R. (2001). Phase I trial of concurrent tirapazamine, cisplatin, and radiotherapy in patients with advanced head and neck cancer. J. Clin. Oncol. 19, 535-542.

Rojas, A., Joiner, M. C., Hodgkiss, R. J., Carl, U., Kjellen, E., and Wilson, G. D. (1992). Enhancement of tumor radiosensitivity and reduced hypoxia-dependent binding of a 2-nitroimidazole with normobaric oxygen and carbogen: a therapeutic comparison with skin and kidneys. Int. J. Radiat. Oncol. Biol. Phys. 23, 361-366.

Secomb, T. W., Hsu, R., Ong, E. T., Gross, J. F., and Dewhirst, M. W. (1995). Analysis of the effects of oxygen supply and demand on hypoxic fraction in tumors. Acta Oncol 34, 313-316.

Segers, J., Crokart, N., Danhier, P., Gregoire, V., Jordan, B. F., and Gallez, B. (2010). Use of xanthinol nicotinate as a co-treatment for radioand chemo-therapy in experimental tumors. Int. J. Cancer 126, 583-588.

Shichiri, M., Hirata, Y., Nakajima, T., Ando, K., Imai, T., Yanagisawa, M., Masaki, T., and Marumo, F. (1991). Endothelin-1 is an autocrine/paracrine growth factor for human cancer cell lines. J. Clin. Invest. 87, 1867-1871.

Shoemaker, J. P., and Dagher, R. K. (1979). Remissions of mammary adenocarcinoma in hypothyroid mice given 5-fluorouracil and chloroquine phosphate. J. Natl. Cancer Inst. 62, 1575-1578.

Simon, N., Jolliet, P., Morin, C., Zini, R., Urien, S., and Tillement, J. P. (1998). Glucocorticoids decrease cytochrome $c$ oxidase activity of isolated rat kidney mitochondria. FEBS Lett. 435, 25-28.

Sonveaux, P. (2008). Provascular strategy: targeting functional adaptations of mature blood vessels in tumors to selectively influence the tumor vascular reactivity and improve cancer treatment. Radiother. Oncol. 86, 300-313.

Sonveaux, P., Brouet, A., Havaux, X., Gregoire, V., Dessy, C., Balligand, J. L., and Feron, O.
(2003). Irradiation-induced angiogenesis through the upregulation of the nitric oxide pathway: implications for tumor radiotherapy. Cancer Res. 63 1012-1019.

Sonveaux, P., Dessy, C., Brouet, A., Jordan, B. F., Gregoire, V., Gallez, B., Balligand, J. L., and Feron, O. (2002). Modulation of the tumor vasculature functionality by ionizing radiation accounts for tumor radiosensitization and promotes gene delivery. FASEB J. 16 , 1979-1981.

Sonveaux, P., Dessy, C., Martinive, P., Havaux, X., Jordan, B. F., Gallez, B., Gregoire, V., Balligand, J. L., and Feron, O. (2004). Endothelin-1 is a critical mediator of myogenic tone in tumor arterioles: implications for cancer treatment. Cancer Res. 64 3209-3214.

Sonveaux, P., and Feron, O. (2005). "Nitric oxide and tumor biology," in Nitric Oxide, Cell Signaling, and Gene Expression, eds S. Lamas and E. Cadenas (Boca Raton: CRC Press), 393-418.

Sonveaux, P., Frerart, F., Bouzin, C., Brouet, A., DeWever, J., Jordan, B. F., Gallez, B., and Feron, O. (2007a). Irradiation promotes Akttargeting therapeutic gene delivery to the tumor vasculature. Int. J. Radiat. Oncol. Biol. Phys. 67, 1155-1162.

Sonveaux, P., Lobysheva, I. I., Feron, O., and McMahon, T. J. (2007b). Transport and peripheral bioactivities of nitrogen oxides carried by red blood cell hemoglobin: role in oxygen delivery. Physiology (Bethesda) 22, 97-112.

Sonveaux, P., Jordan, B. F., Gallez, B., and Feron, O. (2009). Nitric oxide delivery to cancer: why and how? Eur. J. Cancer 45, 1352-1369.

Sonveaux, P., Kaz, A. M., Snyder, S. A., Richardson, R. A., CardenasNavia, L. I., Braun, R. D., Pawloski, J. R., Tozer, G. M., Bonaventura, J., McMahon, T. J., Stamler, J. S., and Dewhirst, M. W. (2005). Oxygen regulation of tumor perfusion by Snitrosohemoglobin reveals a pressor activity of nitric oxide. Circ. Res. 96, 1119-1126.

Stamler, J. S., Jia, L., Eu, J. P., McMahon, T. J., Demchenko, I. T., Bonaventura, J., Gernert, K., and Piantadosi, C. A. (1997). Blood flow regulation by S-nitrosohemoglobin in the physiological oxygen gradient. Science 276, 2034-2037.

Stone, H. B., Brown, J. M., Phillips, T. L., and Sutherland, R. M. (1993). Oxygen in human tumors: correlations between methods of measurement and response to therapy. Summary of a workshop held November 19-20, 1992, at the National Cancer Institute, Bethesda, Maryland. Radiat. Res. 136, 422-434.

Stratmann, A., Risau, W., and Plate, K. H. (1998). Cell type-specific expression of angiopoietin-1 and angiopoietin-2 suggests a role in glioblastoma angiogenesis. Am. J. Pathol. 153, 1459-1466.

Swartz, H. M., Khan, N., Buckey, J., Comi, R., Gould, L., Grinberg, O. Hartford, A., Hopf, H., Hou, H., Hug, E., Iwasaki, A., Lesniewski, P., Salikhov, I., and Walczak, T. (2004). Clinical applications of EPR: overview and perspectives. NMR Biomed. 17, 335-351.

Tatum, J. L., Kelloff, G. J., Gillies, R. J., Arbeit, J. M., Brown, J. M., Chao, K. S., Chapman, J. D., Eckelman, W. C., Fyles, A. W., Giaccia, A. J., Hill, R. P., Koch, C. J., Krishna, M. C., Krohn, K. A., Lewis, J. S., Mason, R. P., Melillo, G., Padhani, A. R., Powis, G., Rajendran, J. G., Reba, R., Robinson, S. P., Semenza, G. L., Swartz, H. M., Vaupel, P., Yang, D., Croft, B., Hoffman, J., Liu, G., Stone, H., and Sullivan, D. (2006). Hypoxia: importance in tumor biology, noninvasive measurement by imaging, and value of its measurement in the management of cancer therapy. Int. J. Radiat. Biol. 82, 699-757.

Theodossiou, C., Skrepnik, N., Robert, E. G., Prasad, C., Axelrad, T. W., Schapira, D. V., and Hunt, J. D. (1999). Propylthiouracilinduced hypothyroidism reduces xenograft tumor growth in athymic nude mice. Cancer 86 1596-1601.

Thomas, C. D., Chavaudra, N., Martin, L., and Guichard, M. (1994). Correlation between radiosensitivity, percentage hypoxic cells and pO2 measurements in one rodent and two human tumor xenografts. Radiat. Res. 139, 1-8.

Tofts, P. S., Brix, G., Buckley, D. L., Evelhoch, J. L., Henderson, E., Knopp, M. V., Larsson, H. B., Lee, T. Y., Mayr, N. A., Parker, G. J., Port, R. E., Taylor, J., and Weisskoff, R. M. (1999). Estimating kinetic parameters from dynamic contrast-enhanced $\mathrm{T}(1)$ weighted MRI of a diffusable tracer: standardized quantities and symbols. J. Magn. Reson. Imaging 10, 223-232.

Tong, R. T., Boucher, Y., Kozin, S. V., Winkler, F., Hicklin, D. J., and Jain, R. K. (2004). Vascular normalization 
by vascular endothelial growth factor receptor 2 blockade induces a pressure gradient across the vasculature and improves drug penetration in tumors. Cancer Res. 64, 3731-3736.

Vanin, A. F., Bevers, L. M., SlamaSchwok, A., and van Faassen, E. E. (2007). Nitric oxide synthase reduces nitrite to NO under anoxia. Cell. Mol. Life Sci. 64, 96-103.

Vaupel, P., Okunieff, P., and Neuringer, L. J. (1989). Blood flow, tissue oxygenation, $\mathrm{pH}$ distribution, and energy metabolism of murine mammary adenocarcinomas during growth. Adv. Exp. Med. Biol. 248, 835-845.
Vujaskovic, Z., Rosen, E. L., Blackwell, K. L., Jones, E. L., Brizel, D. M., Prosnitz, L. R., Samulski, T. V., and Dewhirst, M. W. (2003). Ultrasound guided pO2 measurement of breast cancer reoxygenation after neoadjuvant chemotherapy and hyperthermia treatment. Int. J. Hyperthermia 19, 498-506.

Zhao, D., Jiang, L., and Mason, R. P. (2004). Measuring changes in tumor oxygenation. Meth. Enzymol. 386, 378-418.

Zlotecki, R. A., Baxter, L. T., Boucher, Y., and Jain, R. K. (1995). Pharmacologic modification of tumor blood flow and interstitial fluid pressure in a human tumor xenograft: network analysis and mechanistic interpretation. Microvasc. Res. 50, 429-443.

Zweier, J. L., Samouilov, A., and Kuppusamy, P. (1999). Non-enzymatic nitric oxide synthesis in biological systems. Biochim. Biophys. Acta $1411,250-262$.

Conflict of Interest Statement: The authors declare that the research was conducted in the absence of any commercial or financial relationships that could be construed as a potential conflict of interest.

Received: 23 January 2012; paper pending published: 24 February 2012; accepted:
30 April 2012; published online: 21 May 2012.

Citation: Jordan BF and Sonveaux $P$ (2012) Targeting tumor perfusion and oxygenation to improve the outcome of anticancer therapy. Front. Pharmacol. 3:94. doi: 10.3389/fphar.2012.00094 This article was submitted to Frontiers in Pharmacology of Anti-Cancer Drugs, a specialty of Frontiers in Pharmacology. Copyright (C) 2012 Jordan and Sonveaux. This is an open-access article distributed under the terms of the Creative Commons Attribution Non Commercial License, which permits non-commercial use, distribution, and reproduction in other forums, provided the original authors and source are credited. 